\title{
Biochar as multi-purpose sustainable technology: experiences from projects in Tanzania
}

\author{
Anders Hansson ${ }^{1}$ (D) - Simon Haikola ${ }^{2} \cdot$ Mathias Fridahl $^{1} \cdot$ Pius Yanda $^{3}$. \\ Edmund Mabhuye $^{3} \cdot$ Noah Pauline $^{3}$
}

Received: 18 December 2019 / Accepted: 8 June 2020 / Published online: 19 June 2020

(c) The Author(s) 2020

\begin{abstract}
Biochar was recently included as a promising negative emissions technology (NET) in the Special Report on Global Warming of $1.5{ }^{\circ} \mathrm{C}$ published by the Intergovernmental Panel on Climate Change. Unlike other NETs, it can potentially be used to mitigate global climate change while adding to local resilience in countries highly exposed and sensitive to impacts of climate change, such as least-developed countries (LDCs). The study is as an empirical contribution to the, as of yet, underdeveloped literature on deployment of negative emissions technologies in LDCs in general and on biochar use in developing countries and LDCs specifically. Nine historical and existing biochar projects in Tanzania are mapped in order to analyse problems, goals and common trade-offs associated with smallto medium-scale biochar production in LDCs. The mapping is based on a literature and document study, interviews with project actors, and on-site visits to biochar projects during 2019. The paper gives support to the observation made in the biochar literature that while biochar has many potential socio-economic and environmental benefits, combining them in one single project is difficult. It is concluded that implementing biochar projects in Tanzania will likely involve trade-offs between the development and subsistence strategies and needs of local communities, the motivational forces of different project participants, and the uneven regulatory capacity of the state. We end by reflecting on the use of biochar projects to offset carbon emissions made elsewhere.
\end{abstract}

Keywords Biochar $\cdot$ Least-developed country $\cdot$ Tanzania $\cdot$ Biowaste $\cdot$ Negative carbon dioxide emissions

Anders Hansson

andha@tema.liu.se

1 Department of Thematic Studies: Environmental Change and Centre for Climate Science and Policy Research (CSPR), Linköping University, Linköping, Sweden

2 Department of Thematic Studies: Technology and Social Change and Centre for Climate Science and Policy Research (CSPR), Linköping University, Linköping, Sweden

3 Institute of Resource Assessment, University of Dar es Salaam, Dar es Salaam, Tanzania 


\section{Introduction}

Biochar was recently included as a promising negative emissions technology (NET) in the Special Report on Global Warming of $1.5{ }^{\circ} \mathrm{C}$ (IPCC 2018, Chapters 2 and 4) produced by the Intergovernmental Panel on Climate Change (IPCC). Its theoretical potential is assumed to be significantly lower than that for bioenergy with carbon capture and storage, and direct air capture. Smith (2016) estimates the theoretical potential to be $0.7 \mathrm{GtCeq} /$ year (together with soil carbon sequestration).

Other than its mention in the Special Report on Global Warming of $1.5^{\circ} \mathrm{C}$, biochar has been accorded limited attention in the IPCC reports to date. So far, the substantial efforts of biochar proponents to make biochar an officially recognised mitigation technology by connecting it to the clean development mechanism (CDM) have been unsuccessful (Biochar International 2018; Maraseni et al. 2010). However, Schmidt et al. (2018) argue that biochar is likely to gain importance in climate policy contexts in the coming years, and Smith (2016) argues for its inclusion in integrated assessment models because of its advantages over other NETs.

Unlike other NETs, biochar brings several important co-benefits at a relatively low cost (Lehmann et al. 2006; Scholz et al. 2014). Therefore, it could potentially be used to mitigate global climate change while adding to local resilience in countries highly exposed and sensitive to impacts of climate change, such as least-developed countries (LDCs). In addition, biochar can positively affect crop yields and soil health at relatively low cost, without compromising energy security (Adegbeye et al. 2020; Scholz et al. 2014; Whitman \& Lehmann 2009). In the present paper, we map historical and existing biochar projects in Tanzania in order to analyse problems, promises and common trade-offs associated with small- to medium-scale ${ }^{1}$ biochar production in LDCs. We identify and discuss nine projects and conclude by reflecting at a very general level on the implication of these experiences for the potential inclusion of biochar as an offset mechanism in international carbon markets or regimes.

While biochar offers several potential co-benefits in an LDC context, achieving them in practice is complicated by a number of factors. Life-cycle assessments show that the carbon sequestration ability of biochar is highly context dependent and varies depending on feedstock and the conversion process (Gaunt and Lehmann 2008; Cowie et al. 2015; Joseph et al. 2015; Roberts et al. 2010). Such variability is equally evident in relation to the effect on crop productivity (Jeffery et al. 2011). Furthermore, Swilling et al. (2016) argue that any form of socio-technical innovation in LDCs, targeting climate objectives, will always have to be balanced against the national and local populations' development strategies. Similarly, Shackley and Carter (2014) highlight the importance of tailoring biochar projects among lower-income households to local needs. This balancing act limits the scope of how determinative global climate mitigation objectives should be when considering interventions in national energy systems. Complicating the issue is the relative importance of informal over formal institutions in LDCs, i.e. influence of culture, religious beliefs, traditions and other norms, which significantly affect the path dependencies in the development of rural energy systems (Ramos-Mejía et al. 2018; Wieczorek 2018). In Tanzania such informal institutions interact with formal institutions with a history of unevenly and

\footnotetext{
1 'Small scale' refers to production in repurposed oil drums or smaller retort kilns, whereas 'medium scale' refers to container-size production.
} 
unpredictably applied regulatory capacities, thus creating a 'fractured' environmental state (Robbins 2008) with significant gaps and diffuse relations of power between local communities, various state authorities and foreign and private actors (e.g. Beusekom and Hodgson 2000; Death 2012; Gould and Ojanen 2003; Hansson et al. 2019; Locher and Sulle 2014; Lund et al. 2016; Luttrell and Pantaleo 2008).

Implementing biochar projects in Tanzania will therefore likely involve trade-offs between the development and subsistence strategies and needs of local communities, the motivational forces of different project participants and the uneven regulatory capacity of the state. Based on a literature and document study, interviews with project actors and onsite visits to biochar projects in Tanzania, the aim of this study is twofold: first, to map similarities and diversity of Tanzanian projects presented under the label of biochar, and second, to demonstrate how trade-offs between project objectives, local needs and regulatory capacities have been made in practice. The study is primarily to be viewed as an empirical contribution to the, as of yet, underdeveloped literature on the deployment of negative emissions technologies in LDCs in general (Anderson and Peters 2016; Buck 2016; Creutzig et al. 2015; Fuss et al. 2014; Geden 2015; Gough et al. 2018) and on biochar use in developing countries and LDCs specifically (Mehmood et al. 2017; for case studies in developing countries, see, for example, Joseph et al. 2015; Scholz et al. 2014; Shackley and Carter 2014). Moving beyond the empirical analysis, however, we will conclude by reflecting on the implications of our findings for future approaches to biochar as a mitigation technology in the context of the literature on offset mechanisms in international carbon markets or regimes in LDCs.

\section{Background}

Sustainability research has identified a need for increased contextual awareness in studies of technological development and adoption in developing countries, because many of the standard assumptions about such processes are anchored in a developed country institutional frame (e.g. Hansen et al. 2018; Wieczorek 2018). This imperative is made even more urgent by the fact that integrated assessment models, which are used by the IPCC in their reports on future global carbon emissions trajectories, often include least-developed countries (LDCs) like Tanzania as important as carbon sinks and for the deployment of huge quantities of carbon removal technologies (Harper et al. 2018).

Incorporating LDCs in global mitigation strategies is problematic because such strategies tend to overlook barriers to technology transfer from developed countries (e.g. Verbong et al. 2010). The potential for transferring technologies to a developing or LDC context is often complicated by the presence of ill-functioning institutions (Ramos-Mejía et al. 2018) and widespread poverty (Swilling et al. 2016). Particularly, the latter poses a crucial challenge for sustainable technology deployment in LDCs, and Romijn et al. (2010) identify the fusion of environmental sustainability with social sustainability as the most urgent task in the engagement of developing countries in global mitigation efforts.

Biochar, i.e. the char from pyrolyzed biomass, ${ }^{2}$ offers a rare opportunity for such a fusion. If used in combination with suitable fertilisers, biochar has been shown to

\footnotetext{
${ }^{2}$ Defined by the IPCC (2018) as: 'Stable, carbon-rich material produced by heating biomass in an oxygenlimited environment. Biochar may be added to soils to improve soil functions and to reduce greenhouse gas emissions from biomass and soils, and for carbon sequestration' (Glossary).
} 
significantly improve agricultural yield, even though results are highly context dependent and may range from highly positive to negative (Kavitha et al. 2018; Shabaan et al. 2018; Spokas et al. 2012). Field results from Kenya have shown positive effects on crop yields (Kimetu et al. 2008; Kätterer et al. 2019), though not inconclusively (Güereña et al. 2015). Biochar may strengthen both the nutrient retention (Hagemann et al. 2017) and water retention (Mulcahy et al. 2013) capability of soils, may positively affect biotic interactions (Thies et al. 2015) and remedy acidic soils through its liming effect (Verheijen et al. 2010), while also absorbing pollutants (Beesley and Marmiroli 2011), thus providing a range of potential benefits for agriculture in stressed and vulnerable contexts. Since it can be produced from waste feedstocks, it also has the important potential to reduce deforestation (Yaman 2004). The feedstock aspect is crucial in evaluations of biochar systems, not only because it is highly determinative of biochar characteristics (e.g. Barrow 2012) but also because it determines whether environmental benefits outweigh negatives on aggregate (Alberti 2013; Cowie et al. 2015). Finally, because the carbon in the biochar is stable, its application provides climate mitigation opportunities (Woolf et al., 2010). Consequently, because of the poor state of its soils, vulnerable populations and severely stressed forests, the continent of Africa has been identified as a site where small-scale biochar projects could play an important role in creating local benefits while offsetting carbon emissions from other regions (Adegbeye et al. 2020; Whitman and Lehmann 2009; see also Middendorf et al. 2017; World Bank 2013).

The basic technique of wood carbonisation is ancient, having been practiced for centuries (Garcia-Nunez et al. 2017). In Tanzania alone, charcoal production contributes approx. USD 650 million corresponding to about 2\% of GDP (FAO 2017). Thus, the cultural barrier to technology transfer would seem to be drastically lower for biochar than for other, more alien, mitigation technologies.

Whereas large-scale biofuel production in Tanzania has often given rise to land use conflicts (Jumbe et al. 2009; Mshandete 2011; Mwansasu and Westerberg 2014; Sosovele 2014), biochar derived from waste biomass would not necessitate new plantations. Thus, instead of posing a risk of food security, as several other mitigation technologies could do, biochar would potentially increase food production through its soil enhancement features (cf. Ernsting and Smolker 2011).

Furthermore, the syngas resulting from the pyrolysis can be used to produce electricity, heat for cooking or can be recirculated to sustain the pyrolysis reaction, making the process highly energy efficient, although this adds technical complexity to the process. If deployed widely, these technologies could contribute to decreasing the reliance on forest-derived charcoal, which currently applies to a huge informal sector of the Tanzanian economy with a tremendous impact on the forest (Rascack 2014). While exact numbers are difficult to obtain, Felix and Gheewala (2011) estimated that charcoal and firewood are the main biomass energy source made from forest biomass, with charcoal dominating the fuel mix. In 2000, charcoal was used by approx. $94 \%$ of all household as a fuel. Furthermore, bio-oil resulting from the carbonisation process can potentially be upgraded for diesel production.

As biomass is the main energy source for cooking and heating in Sub-Saharan Africa, the introduction of pyrolysis technology would benefit from being coupled with both soil conditioning and household energy provision, instead of being configured in stand-alone pyrolysis systems solely for soil application (Gwenzi et al. 2015). Gwenzi et al. (2015) argue that batch reactors for large-scale production of biochar could be a challenge for smallholders. Instead, they suggest that at least initial applications should be restricted to small niches, primarily small gardens for peri-urban and rural households, in order to demonstrate the effects of biochar on soil fertility, water retention and crop yields. In such 
systems, drum kilns and pyrolytic stoves can be constructed from locally available material without the need for advanced technical skills and could be fuelled by biomass from traditional and local sources (see also Billa et al. 2019). As these systems provide energy for cooking and heating, they may also be ideal for poorer households without electricity access (Gwenzi et al. 2015). Continuous reactors are more complex and expensive both to construct and to operate; consequently, they are better suited for medium and large-scale biochar production reliant on centralised feedstock systems. In contrast to the batch reactors, the continuous reactors require a reliable supply of electricity. Gwenzi et al. (2015) point out that more research is needed on stakeholder perceptions and economic incentives, as well as on the institutional and policy frameworks required for different technological scales.

\section{Materials and method}

We have identified Tanzanian biochar projects through broad internet searches (through Google), journal articles (using the SCOPUS database and Google Scholar) and by asking informants (i.e. a snowballing technique). While the risk of missing an occasional project can never be eliminated-especially considering the poor state of record-keeping of similar projects in Tanzania (Locher and Sulle 2014) — we feel confident that we have covered all officially published biochar projects in Tanzania to date (February 2019). As will be apparent in the following analysis, not all projects covered here would qualify for the limited definition of biochar provided by Lehmann and Joseph $(2015$, p. 1) as pyrolyzed biomass 'intended for soil application', but, depending on how the phrase is interpreted they fall under the addendum to this definition: '...or broader for environmental management' (Lehmann and Joseph 2015, p. 1). However, we have been guided by the principle to include all projects that self-identify as biochar projects, regardless of the actual function of biochar within the project, to illustrate the variability with which the concept is used.

All in all, nine projects were identified, spanning from research and aid projects to commercial operations (see Table 1, "Appendix 1"), located in 17 districts (Fig. 1). Most projects (7) have been formally concluded, but of these one has been sustained thanks to local initiatives without international support, and two are still ongoing on a commercial basis.

Following the identification of biochar projects, a total of 41 interviews have been conducted with project participants (see Table 2 in "Appendix 2"). Most interviews were conducted in person in February 2019, in the Tanzanian cities Arusha, Dar es Salaam, Kilosa, Morogoro, Mtwara, Mwanza and Tanga. We also visited seven of the project sites and briefly inspected kilns, pyrolysers and, when possible, the farm plots to which biochar had been applied. In addition, complementary Skype or WhatsApp interviews have been held with people living in other parts of Tanzania (Iringa and Mbozi) or outside Tanzania (Canada, Germany, Norway and the USA). These were conducted in January, March and May 2019. In a few instances, group interviews were conducted, but the large majority of interviews were held with one person at a time. All interviews followed the same semistructured interview guide [see the supplementary material (“Appendix 2")]. Information about the purpose of the interviews was provided to participants on each occasion, and oral consent from informants for the interviews to be used for research purposes was obtained in all instances. Complementary project data have been collected through the study of peerreviewed literature and reports, including outreach reports, reports to financing bodies and field reports. 


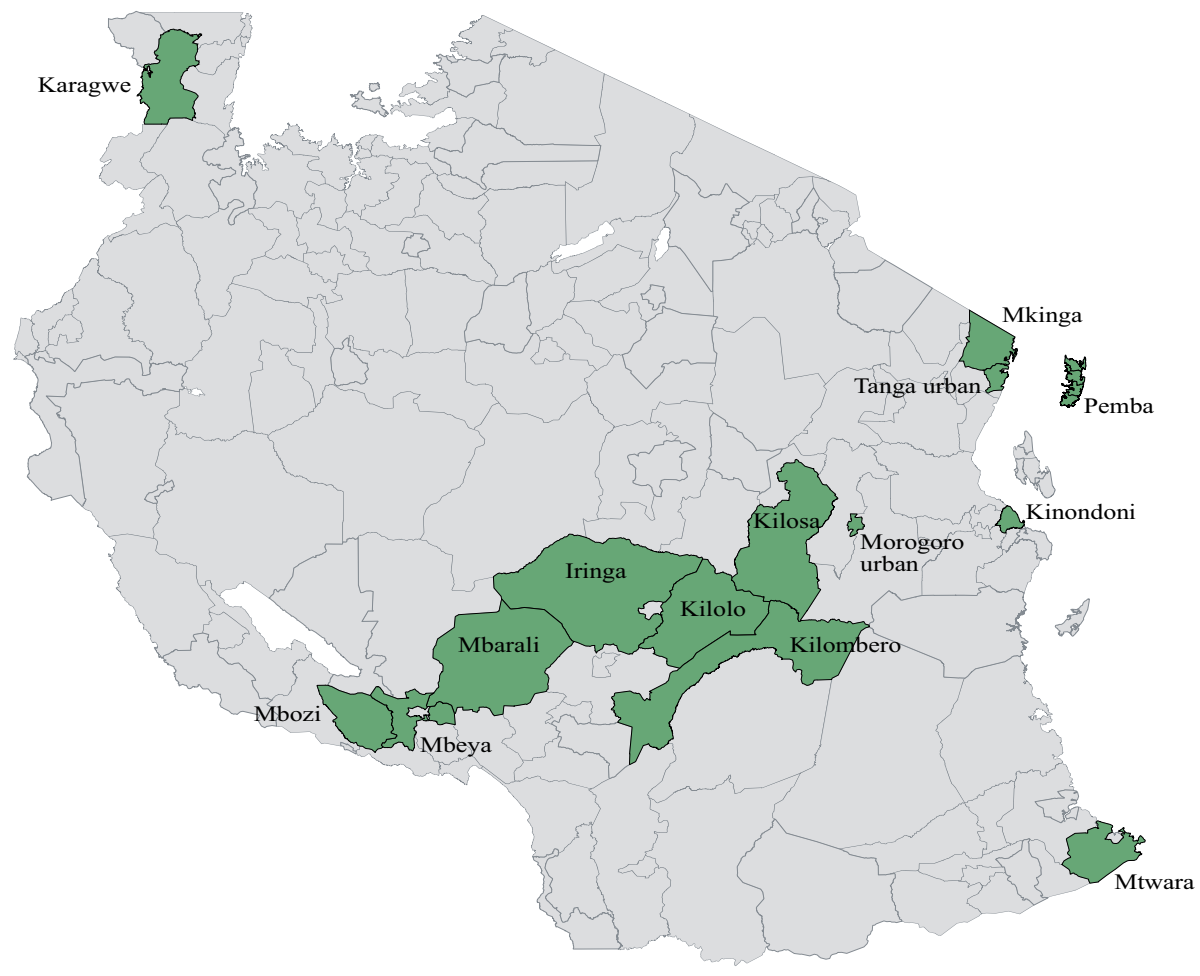

Fig. 1 Map of districts with biochar projects

The data have been analysed with a focus on how biochar has figured within the project, which rationale has been dominant in setting up the project, which challenges and tradeoffs have been encountered and how they have been managed, and the rationale behind the concept of using biochar in the project. Interviews have been cited only in cases where they have yielded results that could not be obtained from published papers. In cases where stakeholders provide diverging views of the project, we have clarified this uncertainty. Finally, it should be noted that our primary aim has neither been to obtain nor evaluate the effectiveness of biochar application, nor to make technical assessments of pyrolyser technologies, nor to symmetrically assess or evaluate the projects. However, in cases where data for a crude technical assessment have been available, we have summarised the data in the project description in Table 1 (“Appendix 1").

\section{Results}

\subsection{Tembo coffee, MIICO, Radio Lifeline; Mbeya (Project no. 1)}

In 2016, the commercial coffee company Tembo Coffee established a biochar project in collaboration with the Tanzanian non-governmental organisation (NGO) MIICO, which is focused on improving agricultural and marketing possibilities for coffee farmers struggling with low productivity. The 1-year-only project was funded through an Innovation Voucher 
Scheme launched by the Coffee Partnership for Tanzania and was managed by the German Investment Corporation. Tembo and MIICO also engaged the US NGO Radio Lifeline for their expertise from biochar projects in Rwanda (Bidlingmaier 2017; Cosmidis and Siwingwa 2017).

The purpose of the project was to improve coffee yields, soil structure and moisture content in relatively poor soil in Mbeya, thereby serving the needs both of the company and the local producers who delivered coffee beans to Tembo on a contract basis. Furthermore, the project set-up ensured access to biochar and fertilisers for farmers who, under normal circumstances, had difficulty in securing pre-harvest financing for soil treatment (Bidlingmaier 2017). The project was thus totally focused on the soil enhancement capabilities of biochar. However, Radio Lifeline had also promoted its previous project in Rwanda on which the Tanzania project was modelled, as a climate mitigation-related project (Business Wire 2013).

The small kiln used was a relatively simple design that the Rwandan branch of the US-registered NGO Radio Lifeline had previously developed and applied in Rwanda. Dubbed the 'Climate Kiln' it was a repurposed oil drum that produced biochar from waste feedstocks such as corn stalks, rice husks or coffee pulp (Brown 2017). The project first entailed training of Tembo and MIICO staff by Radio Lifeline experts, after which they anchored the project locally by training individual farmers. In the initial phase, the only phase concluded before the project was disbanded, 25 kilns were produced, and a test plot assigned. Systematic tests were conducted to determine the effects of biochar application in combination with various levels of fertiliser and compost. The reported test results were unanimously positive towards biochar with fertiliser treatment, demonstrating significantly increased yield and quality of the coffee plants, and even improved taste of coffee from biochar-treated plots. Only the produce was tested, so it was not possible to identify changes in the soil structure (Cosmidis and Siwingwa 2017).

By all appearances, the project was well received on the local level, with farmers having an obvious interest in improving the quality and quantity of their yields (Cosmidis and Siwingwa 2017; Interview 22/1; Personal communication). There were also plans to expand the project by both MIICO, using their own funds, and Tembo (Cosmidis and Siwingwa 2017). In spite of the interest, the project was discontinued after just one harvest season. The reason for the discontinuation, according to one project participant, was new directives from the government, ordering that all cash crops, including coffee beans, to be auctioned and refined domestically within Tanzania. The directive drastically changed the permutations for Tembo Coffee's business model and resulted in the firm withdrawing from the project. Hence, instead of the waste from coffee production, maize cobs, which is a major crop in the region, was identified as a suitable biochar feedstock. Currently, the kilns are reported to still be operated and maintained by the local farmers, without external support, but these activities have not been systematically assessed yet (Interview 22/1).

\subsection{Community Forests International; Pemba (Project no. 2)}

Since 2008, the local environmental NGO start-up Community Forests International (CFI) has been operating on Pemba Island. The aim is to plant trees to strengthen the resilience of the local ecosystem, which is hard pressed both by climate change and local use of charcoal (RGZ 2013). Over time, the strategy of the start-up became increasingly focused on improving local cooking methods. Just like mainland Tanzania, the population of Pemba Island is heavily dependent on charcoal and wood for its energy. Targeting the massive use 
of forest biomass in inefficient 'three-stone' cooking fires was therefore identified as a key sustainability lever (Hardie 2016).

The original plan was to introduce a so-called top-lit updraft gasifier stove, a relatively inexpensive technology that can be used simultaneously for cooking-using the pyrolysis gases - and for production of biochar. However, various considerations forced the organisation to reconsider. Despite its relative simplicity, the technology was judged to be too complex for local implementation. There were concerns it would be perceived as alien, disrupting local cooking practices and the taste of the traditional cuisine. According to the project leader, a crucial insight behind the decision to abandon the plans for biochar production was that theoretical win-win situations-'stacking functions', in the project leader's words - are difficult to put into practice (Hardie 2016; Interview 8/3). As he explained, the project team at Pemba was interested in biochar because of its potential to enhance food security while simultaneously decreasing pressure on the local forest if substituting firewood with waste, as well as its contribution to mitigating climate change. In practice, however, it soon became evident that the order of priority between these different aspects necessitated trade-offs. Since food security was the primary concern in the project, providing more efficient cooking stoves rather than biochar kilns was deemed to have higher priority.

Instead of biochar kilns, three other technologies have been investigated: First, a wooden press that compresses waste feedstocks such as sawdust, rice husks and charcoal dust into briquettes that can be used for cooking instead of charcoal from primary biomass. Local women who have taught the pressing processes to five communities have since spread the technology. Second, experiments were conducted with a so-called Improved Charcoal Production System, a low-cost retort kiln that doubles production efficiency while also reducing air pollution. Thereby, charcoal demand is vastly reduced, even though there is continued dependence on forest outtake (Adam 2009).

Third, since 2012 CFI has been helping to spread a simple cooking stove designed by a local woman. Together, this local engineer and CFI have spread the technology on Pemba by educating around 140 women in how to manufacture and handle the stove. This has resulted in well over 600 stoves that have also been a source of income for the producers, who have been able to make gradual improvements to the design over time. Reducing the amount of wood needed by half, the design reduces the effort needed for fuel collection as well as the impact on the forest, though, again, it does not eliminate the need for forest outtakes (Interview 8/3). By the time of our interview with the project leader, these stoves were in use and well taken up by local farmers. CFI is, nonetheless, still considering implementing biochar projects if they find a suitable technology (Interview 8/3).

\subsection{Sodexo, Pro-Natura and Agricultural Training Institute; Mtwara (Project no. 3)}

In 2012, the French food service company Sodexo was contracted to cater for British Gas, which was operating on the cost of Mtwara in southern Tanzania. As part of its corporate social responsibility profile, British Gas wanted to engage local farmers and therefore made contact with the international NGO Pro-Natura, which had reported great success with a 'Super Vegetable Garden' biochar project in Algeria. Pro-Natura agreed to supply Sodexo with the required expertise on biochar application, while Sodexo made arrangements with the Agricultural Training Institute in Mtwara to act as an intermediary with the local farmers (Interview 15/2). 
Unlike the Pro-Natura project in Algeria, the Mtwara Super Vegetable Garden would not involve biochar production. Instead, normal charcoal would be bought on the market by Sodexo agents, and then distributed to farmers and applied to the soil together with fertiliser and manure. Whereas the climate mitigation dimension of biochar use was a central part of Pro-Natura's project communications about the project in Algeria (Pro-Natura 2012), neither Sodexo representatives nor the participants from the Agricultural Training Institute seem to have taken an interest in this. Farmers themselves perceived the charcoal as normal fertiliser, even though they had to apply it in a new, labour-intensive way (Interviews $15 / 2,25 / 2$ ).

Logically, then, there were no tests on the soil sequestration capabilities of the applied charcoal, but systematic tests were conducted on yield improvement (Sodexo n.d.B). A group of local widows were engaged under the name of the Mtwara Women Perseverance Group and were trained by Pro-Natura and Agricultural Training Institute experts. Sodexo supplied water, tools and fertilisers, which would have been too expensive for the local women to buy on their own, especially given the poor state of the soil. The project appears to have functioned well up to harvest, but there are diverging accounts of whether payment was ever provided, and indeed whether pay was part of the agreement (Interviews 15/2, 25/2).

The project was described as a 'success story' by Sodexo representatives (Interview $15 / 2$; Sodexo n.d.) and, according to unpublished reports, yields were drastically improved in three out of four test crops (Sodexo n.d.; Sodexo n.d.B). However, it was quickly disbanded when Sodexo moved out of Mtwara relatively soon thereafter. Representatives of the Women Perseverance Group claim they participated in the belief that the contract would be long term, and that there was simply no way they could maintain the labourintensive and expensive farming techniques on their own; the latter aspect being corroborated by the intermediary from the Agricultural Training Institute (Interviews 25/2). The Sodexo representative, on his part, argues that the deal was always limited to first harvest, and that he tried in vain to encourage the women to maintain the newly acquired farming techniques and market the produce (Interview 15/2).

\subsection{Swiss Agency for Development and Cooperation, and the University of Dar es Salaam; Dar es Salaam (Project no. 4)}

The project received funding from the Swiss Agency for Development and Cooperation (SDC) and involved researchers from the University of Dar es Salaam, the Swiss Federal Institute of Aquatic Science and Technology and the Massachusetts Institute of Technology. The project was motivated by the estimations of potentials for improvement in waste management practices in Dar es Salaam, which showed that municipal solid waste could replace $10 \%$ of the daily consumed wood-based charcoal in the city (Lohri et al. 2015). The aim of the project, which is documented in one scientific publication (Lohri et al. 2015), was to investigate the potential for producing char from solid biowaste in Dar es Salaam and to develop a framework for identifying and assessing the most suitable biowaste feedstocks for decentralised carbonisation. By doing so, the project would also provide information on how to simultaneously enhance the systems for solid waste management, as well as how to address cooking fuel challenges (Lohri et al. 2015). While the project was never aimed at commercialisation, it should result in a verdict on the pyrolysis unit's technical functionality, the financial viability of the system, the identification of suitable feedstocks and, finally, a discussion of dissemination potential. 
The char was never intended for agricultural use or soil enhancement, and the climate mitigation potential was framed as being of secondary importance. Still, the term biochar is mentioned as a keyword in the scientific publication (Lohri et al. 2015) that resulted from the project. Furthermore, the increased general interest in biochar as a method for climate mitigation and its application to soils was acknowledged as a contextual factor of importance by project participants (Interview 19/2, 22/2) and was briefly reviewed in the publication (Lohri et al. 2015).

The investigated waste feedstocks were bagasse, potato peelings, coconut shells/husks, trimmings/pruning, cardboard, wood waste and seaweed. The three most suitable biowaste types (packaging grass/leaves, wood waste and cardboard) were identified based on a multi-criteria analysis including criteria for availability, accessibility and physicochemical properties. Samples of these were collected and carbonised in a low-tech and small-scale experimental pyrolysis unit at the University of Dar es Salaam's Campus area. The experimental pyrolysis system had the capacity to process eight batches per day after addition of up to $800-1000 \mathrm{~kg}$ waste. It was concluded that the requirements for an efficient pyrolysis process - the use of dry, unmixed, homogeneous and uncontaminated feedstock with low ash content that could be collected close to the pyrolysis unit-made the majority of the solid biowaste in cities unsuitable (Lohri et al. 2015).

The char was produced in a unit that consisted of three components; pyrolysis reactor, heating system and heat-retaining brick kiln. The design was relatively simple and small scale, with a $200-\mathrm{L}$ oil barrel used as a reactor inside a burnt clay brick kiln. Employing a semi-batch operation, the process could make use of residual heat generated externally from liquified petroleum gas (LPG) burners for the second barrel. However, the project participants emphasised the need to improve heat recovery to make the system more efficient (Interview 19/2, 22/2, Lohri et al. 2015). The char produced was processed to briquettes, making the system well aligned with the assumed end users' customs, since the use of briquettes would not necessitate significant changes to current cooking practices and appliances (Lohri et al. 2015). Today the unit has been dismantled and stored in the campus area (Interview 19/2, 22/2).

A cost and revenue estimation of the project concluded that the financial viability of the experimental pyrolysis system was unsatisfactory under the given circumstances. A key insight stressed by project participants was that the charcoal market prevailing in Tanzania is largely informal, and prices are therefore impossible to regulate through policy. Any future biowaste-to-char system would therefore need firm, regulatory and governmental support if it is to be possible to implement. Furthermore, a market analysis showed that increasing the availability of low-cost LPG, which is free from air pollution, rendered the system even more uncompetitive (Interview 19/2, 22/2, Lohri et al. 2015).

\subsection{The energy-sanitation-agriculture nexus; Karagwe (Project no. 5)}

In 2010, the non-governmental farmers' organisation MAVUNO, CHEMA and EcoSan together with Engineers Without Borders Germany and the University of Technology in Berlin, initiated two projects in Karagwe, located in the Kagera region in northwest Tanzania. The projects aimed to counteract deforestation and soil nutrient depletion while also improving sanitation, primarily by developing locally adapted low-tech designs among poor households without livestock (Krause 2015; Krause and Rotter 2018). The ambition was to combine bioenergy and sanitation services in order to construct an integrated system covering (1) energy supply for cooking, (2) sanitation of human faeces and urine and 
(3) soil fertility and reforestation. The plan was to conduct pilot studies and, after assessment and completion, develop a strategy with local actors for implementing the technologies in the smallholder communities.

The biochar was primarily framed as a soil amendment supplement and as a promising compost additive. It was produced in low-tech microgasifier stoves fuelled using dry harvest residues, e.g. coffee shells (Krause and Rotter 2018), or, alternatively, the biochar was recovered from the sanitation processes. Mixed with compost that was used as soil amendment, the biochar had a climate mitigating potential; however, climate mitigation was not prioritised, and emissions of greenhouse gases potentially increased with the new practices when compared to current state practices (Krause and Köppel 2018). Nonetheless, the potential for climate mitigation was discussed and tentative comparisons were made with scientific publications arguing for a general climate mitigation potential for biochar, even though it could not be verified in the current project. The project's German scientists thus reasoned that previously published scientific data on biochar as a soil amendment were contradictory, showing that available data were uncertain and that the effects of biochar amendments are highly site-specific (Krause and Köppel 2018; Krause and Rotter 2018).

In 2014 a one-season plant field experiment was conducted. Three types of compost (standard compost, biogas slurry and biogas slurry with added biochar) were applied to the soil in order to assess the changes to nutrients and water in the soil and to crop yield and plant nutrition. For some crops the change was minor, but for beans and maize, crop biomass production and economic yield were significantly improved by the application of biochar-enriched compost (Krause et al. 2016).

The project was evaluated in a socio-economic assessment among the smallholders and other concerned actors. With regard to six crucial sustainability dimensions, it received positive assessment results mainly for technological/operational, environmental and socioeconomic/financial functions. The negative assessment results referred primarily to political and legal criteria (primarily lack of governmental support). The German project leaders thus concluded that the concept was suitable, on a general level, for sustainable soil management (Krause and Köppel 2018; Krause and Rotter 2018). The international partners are no longer participating in the project, but the local partners sustain some parts of the systems, e.g. production of locally adapted stoves (Interview, 7/5).

\subsection{MASH Energy Ltd. (former MASH Biotech) and Out-Growers Tanzania Ltd.; Tanga and Mkinga (Project no. 6)}

This project is a collaboration between two private companies: MASH Energy Ltd. and Out-Growers Ltd., with complementary business models and competencies. Out-Growers is a private business initiative partly funded by the African Enterprise Challenge Fund (AECF). In 2016, the company was established in the Mkinga District, with the aim of furthering local cashew nut farmers' incorporation into the value chain. The strategy has been to increase their control of the production phase by providing sulphur and to assist in marketing and final sale of the products. The company has helped farmers install processing units to localise the process and also developed plans on how to utilise by-products like the cashew apple (Mosoba 2019). MASH Energy is a spin-out from the Technical University of Denmark, and the general business model involves converting agricultural residues into ISO compliant fuel products, sustainable electricity and fertilisers with a negative carbon footprint (Mash-Energy 2019). The company received an initial DKK 600,000 grant from the University to start up the business, funding that was considered to be a prerequisite for 
the endeavour (Interviews 16/2, 17/2). The underlying prototypes of the technical facilities, which are technically complex and medium scale (container size), were developed and tested in Denmark and later deployed as commercial scale in India. The pyrolysis unit is containerised and modular, thus enabling mobility and easy inter-connection to regional supply of feedstocks and demand of products, with minimal site preparations being required. Furthermore, entire units can be replaced if major service is needed (Mash-Energy 2019).

The idea of processing cashew nut residues, which are suitable for oil production, and turning them into biodiesel was developed and tested in India, but increased competition over cashew nut shells made the business unprofitable. Tanzania was identified as a suitable relocation site, being one of the world's largest producers of cashew nuts. A collaboration was initiated with Out-Growers, who had an established collaboration with local farmers in Tanga, as well as cashew processing skills. Initially, the main product was bio-oil, which could be upgraded to diesel for running furnaces, drying tobacco (which was done by a company in Morogoro) or fuelling generators. Uncondensed gas was also recovered from the process.

At this early stage, biochar was merely considered a by-product without market value, but the project leaders had identified its prospective environmental benefits. Since then, they have been investigating ways to marketise these benefits. Presently, the biochar is provided and distributed free of charge to the local cashew nut farmers who deliver cashew nut residues as feedstock for the centralised pyrolysis unit in the city of Tanga. Out-Growers support the farmers with basic guidelines on how to apply the biochar to the soils. As of yet, the distribution and application of biochar are on an ad hoc basis. The companies still struggle with how to best apply the biochar and have recently started experiments with test seedlings. Currently, there is no monitoring of how and whether the farmers apply the biochar. Out-Growers explain that it is important that the farmers experience concrete and immediate benefits of applying the biochar to the soil, if not, it might be used in line with current customs, i.e. as a cooking fuel, which would negate the climate mitigation benefits (Interviews 16/2, 17/2).

Considering that the Tanzanian government passed a law in 2018 prohibiting export of unprocessed cashew nuts, the prospects for a steadily increasing supply of feedstock are good. This upcoming trend in combination with an increasing demand for carbon neutral fuel in industrialised countries, primarily the maritime industry, provides a basis for MASH's positive outlook on the future. The company also welcomes the idea of incorporating international carbon trade into the current business model, but only if managed directly via the company and not the farmers. According to project leaders, MASH has performed a life-cycle analysis from a systems perspective, including the potential climate mitigation effects of applying biochar to the soils. The report has not yet been scientifically validated, but its tentative results suggest that $1 \mathrm{~kg}$ of oil causes a $6 \mathrm{~kg} \mathrm{CO}_{2}$ reduction in the atmosphere. The company emphasises that the net negative carbon emissions aspect is an important sales pitch when marketing the fuel products towards countries in Europe (Interviews 16/2,17/2).

\subsection{Norges Vel, TaTEDO and RUDI; Dar es Salaam, Mbarali, Kilombero and Idodi (Project no. 7)}

In May 2013, the Royal Norwegian Society for Development (Norges Vel) initiated a biochar project Funded by the Nordic Development Fund. One part of the project, which aimed to improve smallholder livelihoods, was biochar production from rice husks and the simultaneous retention of waste heat and excess syngas for cooking (NCF 2017; Interview 6/2). The charcoal was termed biochar because of its use as a soil amendment, and while the primary purpose was to foster smallholder resilience by increasing yields and reducing climate 
vulnerability, the global climate benefits of avoided methane emissions at decomposition, and removal of carbon dioxide from the atmosphere, were noted as side benefits by the project participants.

Norges Vel would also develop the pyrolyser to be used in cooperation with Tanzania Traditional Energy Development Organization (TaTEDO). However, the pyrolysis unit was soon ruled unfit for purpose based on a previous pilot project using the unit in Uganda when it had several technical breakdowns and was deemed too complex for local use. The Tanzanian unit was centralised, and its construction required material not locally available. A brief assessment of the unit in Zambia, where it was used by farmers poorer than those in the Tanzania project, showed that a much simpler and smaller construction, such as the Kon-Tiki kiln, gave a very similar energy efficiency. This was partly explained by the fact that the larger unit needed firewood to ignite the pyrolysis process, whereas the simpler models could be ignited by the biochar feedstock (Interview 5/2). In addition to the relatively high investment costs, the unit was hard to operate, not least due to the logistical challenges of loading feedstocks from the top of the kiln, some $1.5 \mathrm{~m}$ above ground. In fact, the unit was abandoned even before testing (Interview 27/2). Instead, TaTEDO's more traditional, simple function pyrolysis unit, a drum retort kiln with closed pyrolysis chamber, was used to produce rice husk biochar in Kinondoni, Dar es Salaam. Together with the Rural Urban Development initiative (RUDI), which acted as the local partner responsible for hiring agricultural extension officers, farmers in seven wards in three districts were chosen to test the biochar in rice cultivation. At the time of project closure in 2017, the project had demonstrated positive results, increasing average rice plant height following the application of rice husk biochar, but the technology did not fulfil the cost and reliability requirements. The problems were amplified and not possible to resolve since the local and foreign project partners could not agree on the most optimal kiln design and the management of the project. According to one of the extension officers, the discontinuation of the project left the farmers disappointed, as they had expected a stable supply of biochar (Interview 14/2). Since 2017, TaTEDO occasionally produces charcoal not intended for soil amendment (Interviews, 14/2, 25/2, 27/2).

\subsection{Trans-SEC and Sokoine University; Kilosa (Project no. 8)}

The so-called Trans-SEC project, ${ }^{3}$ funded by the Federal Ministry of Education and Research, and the Federal Ministry for Economic Cooperation and Development in Germany, aimed to improve food security for the rural poor in Tanzania and produce energy from biowaste, i.e. maize cobs (Uckert et al. 2018; Interviews 14/2). Starting in 2013, a set of strategies for sustainable upgrading of local and regional food value chains was developed, including biochar production and use. The University of Hohenheim provided blueprints of a top-lit updraft barrel reactor, which was adapted to local needs by engineers at Sokoine University of Agriculture (SUA) who modified the size, insulated the barrel and enabled the use of excess heat for cooking (Interview, 14/2). Initial tests of the effects of biochar on crop yields (corn) were conducted at SUA, with positive results (Graef et al. 2018; Interviews 14/2, 15/2), and the pyrolysis unit was then piloted in Ilakala village, Kilosa district (Morogoro region).

The farmers used corn cobs as feedstock, a locally abundant waste with no alternative usage. Farmers were told about the positive effects of biochar as a soil amendment, but training and awareness raising were limited due to time shortage (Interview 15/2). As a result, the

\footnotetext{
3 The project's complete name in English is Innovating Strategies to safeguard Food Security using Technology and Knowledge Transfer: A people-centred Approach.
} 
charcoal produced was used as an alternative cooking fuel instead of as a soil amendment. The farmers generally deemed the opportunity cost of using the charcoal as soil amendment to be too high, compared to the benefits of reducing the time spent on collection of fuel wood, and reducing indoor air pollution from wood burning (Interviews 14/2). One professor at Sokoine University associated with the project argued that the relatively high amounts of biochar needed to achieve an increase in corn yields raised the threshold for using the charcoal as a soil amendment (Interview, 14/2). Furthermore, the cooking function of the pyrolysis unit was not well developed, since profuse smoke development restricted its use to outdoor cooking, which was not common in the village. Farmers also reported that it was only useful for shorter cooking times (Interviews 14/2). While the unit was relatively inexpensive and made mostly from locally available material, farmers reported that it broke down after about 2 years of continuous usage and that they were unable to repair it (Interviews 15/2).

The researchers involved in the Trans-SEC project recognised the charcoal produced as biochar due to its intended use as a soil amendment, noting that the charcoal could also be used as cooking fuel, in which case they mostly avoided using the term biochar (Graef et al. 2018; Uckert et al. 2018; Interviewees 14/2). The farmers, on the other hand, mostly signified the charcoal as biochar due to the origin of the feedstock rather than its intended use as a soil amendment or cooking fuel. Producing charcoal from what was previously perceived to be waste, i.e. corn cobs, made this charcoal distinguishable from the most common charcoal sold on the markets, a distinction that was signalled through reserving the term biochar for charcoal produced from waste while cooking fuel produced from pyrolysis of harvested wood was termed charcoal.

\subsection{New Forests Company; Iringa and Mbozi (Project no. 9)}

The East African based New Forests Company (NFC), established in Uganda in 2004, started business in Tanzania in 2009. NFC focuses on tree plantations, production of poles and, since 2015, also sawn timber. The company has an environmental and social sustainability profile (NFC 2019). In a strategy to minimise waste and improve its business case, residues from the core business are converted to tradable commodities, mostly fuels such as charcoal, biochar and firewood. In Tanzania, biochar is produced in the Kilolo district, Iringa region, from eucalyptus wood residues from the production of electricity poles. The biochar is produced in non-continuous, container-size pyrolysis units, held at a production facility that is by far the largest in the industry. According to the company manager, roughly 300 bags of biochar per day are produced here, and the company claims to be the only commercial producer of biochar in the country. The biochar is charged with nutrients from local dairy and chicken farms or imported organic fertilisers, as well as pyroligneous acid which is commonly known as raw wood vinegar and is produced by NFC from condensation of the pyrolysis syngas. Substituting chemical fertilisers, primarily in coffee plantations, is claimed to be one of the main benefits. The wood vinegar, which is a byproduct, is also very profitable according to the manager (Interview 19/3).

A first 30 hectares trial application was conducted in 2019, amending biochar to soils in a coffee plantation in the Mbozi district, Songwe region, and test results report very positive yields. The results are not well documented, however. NFC aims to sell biochar to commercial cash crop farmers rather than subsistence farmers, because the former group is more skilled and easier to establish business contacts with. The demand for biochar and the availability of sustainable feedstock is claimed to be far larger than NFC's production capacity. Considering the abundance of 
sustainable feedstock and the constant degradation of the Tanzanian soils, the manager professes to be highly optimistic concerning the outlook for the business model (Interview 19/3).

NFC brands all its charcoal as sustainable. However, in most cases the company distinguishes between charcoal used as a soil amendment, in which case they term it biochar, or as a renewable fuel, in which case they simply refer to it as charcoal. Climate change is acknowledged by the company as the biggest and most immediate threat to coffee farming in Tanzania, but climate mitigation is not a selling point when reaching out to farmers. Instead, the immediate positive effects of biochar for soil amendment are emphasised. The firm does not have any ambition to connect the business model to carbon markets of any kind, since they consider those markets far too abstract and unreliable (Interview 19/3).

\section{Discussion}

The above-reviewed experiences from all currently reported biochar projects in Tanzania reveal a wide variability in project design and use of the concept of biochar (see Table 1 in "Appendix 1"). Through this diversity, however, a number of trends and patterns can be discerned. From these, generalisable lessons can be drawn about common challenges and trade-offs for small- to medium-scale biochar projects in LDCs.

First is the observation that project rationale determines which aspects of charcoal/biochar properties are highlighted by project leaders in their communication with project participants or external actors. In one of the projects (no. 4), the intention was never to make use of the charcoal in a biochar capacity, even if its potential as such was noted. A majority of the projects (nos. $2,3,5,7,8$ ) have been driven by research aid targets, and as such they tend to focus on the soil enhancement capabilities of biochar rather than its climate mitigation capacity. The latter is often noted rather as an afterthought, or-as in the case of project no. 5-as a topic that is questioned. Three of the projects (nos. 1,6, 9) are commercially driven, and these - for marketing reasons — stress the climate aspect the most.

Second, despite the biophysical identity between charcoal and biochar, social and technological barriers have been significant. It has proven difficult to develop a pyrolyser unit that functions as a cooking device, despite several attempts (nos. 2, 5, 7 and 8). In all these cases except one (no. 5), the technology was perceived to be ill-suited to the local context in which it was to be used and was abandoned either after a relatively short time or before testing (see Sinton et al. 2004). The practice of applying biochar to the soil is associated with a technological barrier that necessitates training and, often, extra resources (nos. 1, 3, 5, 6, 7 and 8). Applying charcoal to the soil can be a social barrier as it is an unfamiliar practice for many local farmers, who either seem to interpret the charcoal to be a traditional fertiliser or to use it in its customary function as a cooking fuel (nos. 3, 5, 7 and 8), and in at least one case (no. 6) it is unclear how the charcoal has actually been used after being distributed to farmers. It should be noted that if the charcoal is thus used as 'sustainable charcoal'-i.e. cooking charcoal produced from sustainable sources - rather than biochar, geographical location would seem to be crucial for the socio-economic viability of the production system (see also Shackley et al. 2011). For example, project no. 4 indicates that the availability of cheap charcoal and LPG in urban regions renders competition extremely difficult for alternative cooking fuels; project no. 8 instead shows that rural farmers find the possibility of producing charcoal from alternative feedstocks as something positive and worthwhile.

The prevalence of socio-technical barriers, in turn, points to the third lesson, which is the apparent difficulty of achieving self-sustenance in biochar projects. All of the reviewed 
projects where biochar has actually been applied have been dependent on external actors providing technology, expertise and material resources. This has been provided through local intermediaries acting in a bridging function and in the literature has been identified as key for the adoption of sustainability technologies in developing countries (Iyang et al. 2014; Kilelu et al. 2011; Klerkx et al. 2011; van Lente et al. 2003; van Welie and Romijn 2018). Of the aid and research-driven projects (nos. 2, 5, 7, and 8), only one (no. 5) reports that parts of the biochar system continue to be maintained after the project leaders have left. Notably, the only aid project (no. 2) that abandoned the idea of biochar for a simpler system design is the only one to report a significant local uptake of the new technology (see Pansera and Sarkar 2016; Smith et al. 2014, for the importance of local adoption for sustainable energy transitions in developing countries). This reflects the tendency of aid programmes, noted by Fridahl et al. (2015), to avoid institutionalising aid. In the context of small- to medium-scale biochar projects in LDCs this is unfortunate, as it risks failing the expectations of vulnerable populations (see further Olwiga et al. 2015), something noted at least in project nos. 7 and 3 (the latter being a corporate social sustainability project rather than an aid project).

The projects that are most easy to sustain over a longer period appear to be the commercial projects (nos. 1, 6 and 9). The commercial incentive provides a powerful driver to monetise by-products by turning them into biochar, and the fact that the users are cash crop farmers who have a somewhat longer planning horizon than sustenance farmers and a direct interest in enhancing yields, further strengthens the long-term viability of these projects. At the same time, however, they are the most vulnerable to the vicissitudes of the product markets and the volatile regulatory landscape of many LDCs (see Project nos. 1 and 6).

The diversity, challenges and contextual specifics of the projects (summarised in Table 1 in "Appendix 1") verify some key observations from the literature. First, that biochar is a rather open concept in which different aspects are stressed in different contexts (Lehmann and Joseph 2015). Second, that choosing which function of biochar to stress must be carefully weighed against the priorities of sustenance and development of vulnerable populations when the project is located in an LDC (Joseph et al. 2015; Swilling et al. 2016). Third, that realising several of biochar's many potentials in a given LDC context-to 'stack functions' in the words of one informant (see Project no. 2) —is often difficult (Lehmann and Joseph 2015; Joseph et al. 2015). These observations have implications for the idea of incorporating biochar as a standard mitigation technology to be used in a portfolio of possible offset mechanisms in international climate politics, argued by some authors as one possible way to realise the multifaceted socio-environmental potential of biochar (Cowie et al. 2015; Lehmann et al. 2006). We will conclude with some reflections on these.

\section{Concluding reflections}

A key dilemma in evaluating biochar projects for the generation of carbon credits is a priori determination of how many of its potential benefits need be fulfilled in order for sustainability to be achieved (Cowie et al. 2015; Gaunt and Driver 2010; Lehmann and Joseph 2015; Verheijen et al. 2009). The trade-offs involved both on the level of practice-e.g. determining its value as a cooking fuel vs its value as a soil amendment - and on the level of soil functions (Verheijen et al. 2009), would necessitate rigorous tests of both socio-economic and biophysical parameters (Verheijen et al. 2012). This kind of testing, most likely entailing advanced monitoring technology (e.g. Paustian et al. 2009), would neither be practical nor desirable in an LDC context, given the need for flexible arrangements evidenced, inter alia, by the projects surveyed in the present paper. 
Furthermore, verification is made difficult by the complex and uncertain state of land tenure in many African nations, as argued by Unruh (2008, p. 705) in relation to carbon sequestration through afforestation and reforestation projects:

Diverse forms of customary tenure is how most Africans continue to get by, and a minority understand how the state tenure system works, how the state works, or hold it to be the prevailing idea with regard to property rights. In the afforestation and reforestation carbon sequestration literature, as well as the forest planting aspects of the CDM, sustainable development and governance are currently connected by a set of assumptions that differ markedly from the African tenurial reality.

Tenure insecurity increases investment risk, in terms of both money and labour capital, as investments may be lost due to transfer of access to land to new holders. This risk is prevalent for both large-scale project investments and smallholder farmers. In both cases, rights to land may be revoked on short notice, rendering the immobile fruit of investments-e.g. soil enhancement through biochar or perennial biochar feedstocks-insecure. In Tanzania, this risk inherent to unclear tenure arrangements is further aggravated by weak and often unpredictable enforcement (Hansson et al. 2019; Lund et al. 2016). ${ }^{4}$

Verification would be facilitated by deploying large-scale biomass plantations with dedicated feedstocks. However, this would be inadvisable for two main reasons. First, the socio-economic and environmental benefit of using waste feedstocks would be foregone, and the associated land use change may well end up eliminating any climate benefit on aggregate (Cowie et al. 2015). Second, the establishment of large-scale plantations of dedicated biomass risks leads to land deprivation, as historical experiences of forced resettlements and imposed restrictions on customary land use in relation to biofuel and forest projects in Tanzania show (Brockington and Ponte 2015; Lund et al. 2016; Olwiga et al. 2015). These results are often due to a mismatch between designations of marginal or unoccupied land in biofuel project plans and actual usage of the land by farmers and nomad populations (Exner et al. 2015; Locher and Sulle 2014; Olwiga et al. 2015).

One way of avoiding the need for centralised project activities, as well as reducing the aforementioned risk of tenure insecurity, would be to pursue biochar projects through an equivalent of the so-called programme of activities under the Clean Development Mechanism (CDM). Under the CDM programme of activities, an unlimited number of component project activities could apply for participation using a standardised methodology, thus enabling the coordinated implementation of small projects that would be unviable as stand-alone projects, due to high costs of verification and monitoring.

Potentially, this could be a way of reducing investment risk for private actors-by adding the revenue stream from carbon finance-and bring large-scale to small-scale projects while avoiding issues with land-grabbing. Such a programmatic approach has, for example, been applied to the diffusion of efficient cookstoves. Lambe et al. (2015), in studying CDM cookstove projects and programmes in Kenya, have shown how carbon finance through CDM can facilitate market creation, provide conditions for monitoring and increase access to after-sales support of equipment. Programme activities could potentially be developed also for biochar (van der Gast and Spijker 2013), considering that most biochar systems in developing nation contexts tend to be small scale, on the household or farm level (Scholz et al. 2014).

However, while this approach would help overcome some obstacles to the realisation of biochar as a standardised mitigation technology, it would not resolve the key issue related to its multi-dimensional character. It would still have to be decided what aspect of biochar that needed

\footnotetext{
${ }^{4}$ It should be noted, however, that biochar would seem to be uniquely secure in terms of mitigation longevity, since-once applied-it tends to remain in the soil for a long time period (e.g. Lehmann et al. 2015).
} 
to be verified-whether it be its application to the soil or the production process, and then how to evaluate the properties and interactions of different system components. There is a marked difference between verifying the mere presence of a cookstove — or even its actual usage - to evaluating, for example, the effects of soil properties at deployment sites on biochar decay rates, the potential loss of soil organic content in cases when biomass is removed from fields for use as a biochar feedstock instead of being left to decompose, and the dependency of potential emissions reductions claimed on the amount and type of fertiliser used. Furthermore, as shown by Lambe et al (2015), carbon finance through the CDM was most important as a complementary revenue stream for project leaders with an already viable product, i.e. efficient cookstoves. The context sensitivity of biochar makes it highly unlikely that one single product may be developed that is easily transferrable in time and space that combines verifiable socio-economic and environmental benefits. Project number 2 in the present survey is an illustrative case of this difficulty.

In relation to the aforementioned problems, the voluntary offset market offers a flexibility that seems more attuned to the multifaceted character of biochar. Voluntary offsets are not in need of the same type of standardisation demanded by compliance credits and would allow for end users of biochar to deviate from stated project intentions without necessarily undermining the offset's viability. Since the market for voluntary offsets has proven more stable than the compliance market (Lambe et al, 2015), it would probably also provide a less risky financial context for projects. It should be stressed that the moral case for insulating LDCslacking historical climate change guilt-from a global compliance carbon market is ultimately inseparable from the practical argument, since carbon offsets may well hinder rather than facilitate energy systems transition in developed countries (Bracking 2015; Carton and Andersson 2017; Edstedt and Carton 2018; Faran and Olsson 2018; McLaren et al. 2019).

Acknowledgements Open access funding provided by Linköping University. The research was funded jointly by the Swedish Research Council and Sida through the Swedish Government's development aid funds, and by Formas' and Forte's research appropriations (Sustainability and Resilience-Tackling Climate and Environmental Changes [2016-06359]).

Open Access This article is licensed under a Creative Commons Attribution 4.0 International License, which permits use, sharing, adaptation, distribution and reproduction in any medium or format, as long as you give appropriate credit to the original author(s) and the source, provide a link to the Creative Commons licence, and indicate if changes were made. The images or other third party material in this article are included in the article's Creative Commons licence, unless indicated otherwise in a credit line to the material. If material is not included in the article's Creative Commons licence and your intended use is not permitted by statutory regulation or exceeds the permitted use, you will need to obtain permission directly from the copyright holder. To view a copy of this licence, visit http://creativecommons.org/licenses/by/4.0/.

\section{Appendix 1}

See Table 1.

\section{Appendix 2}

See Table 2 . 


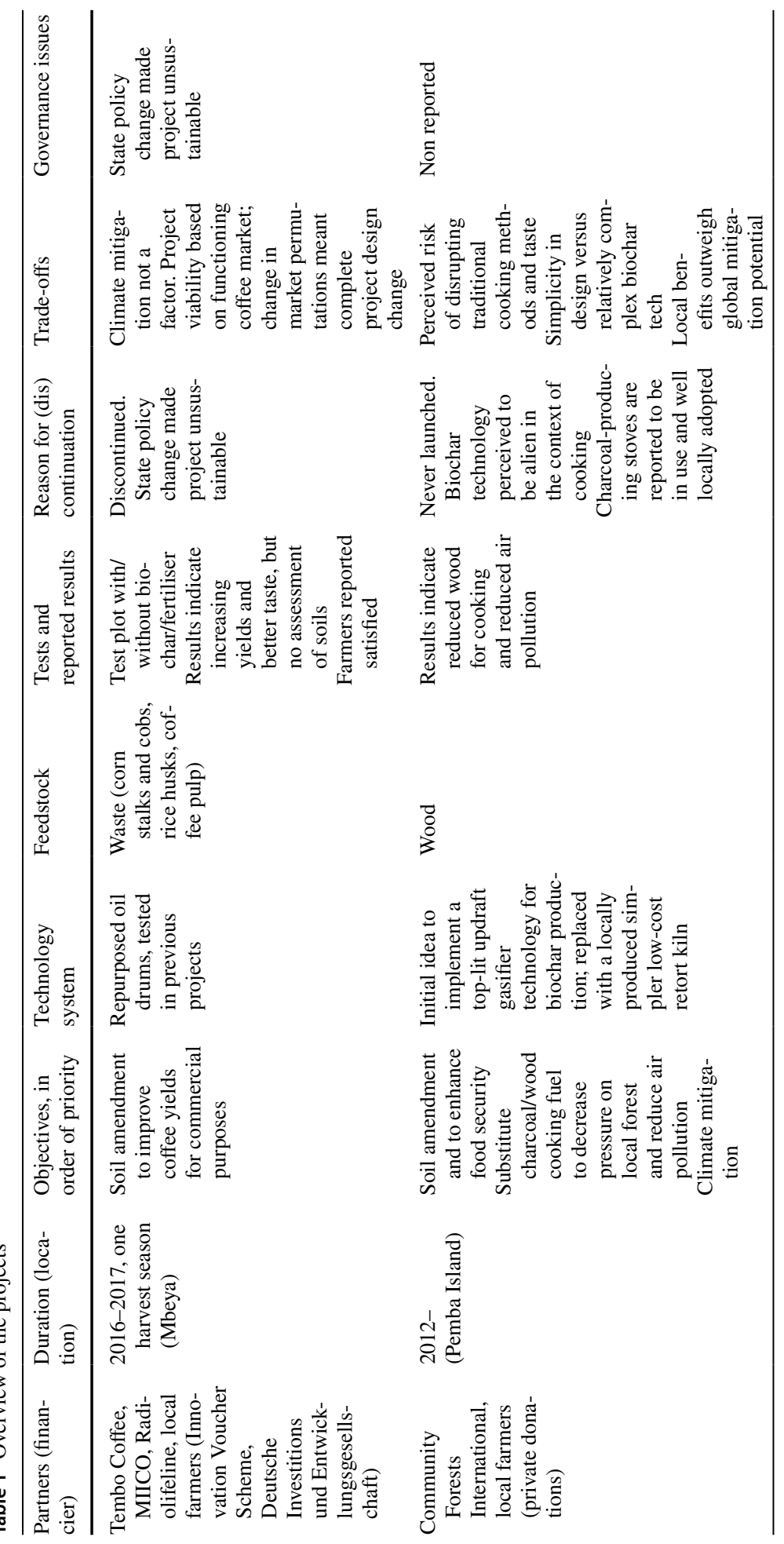




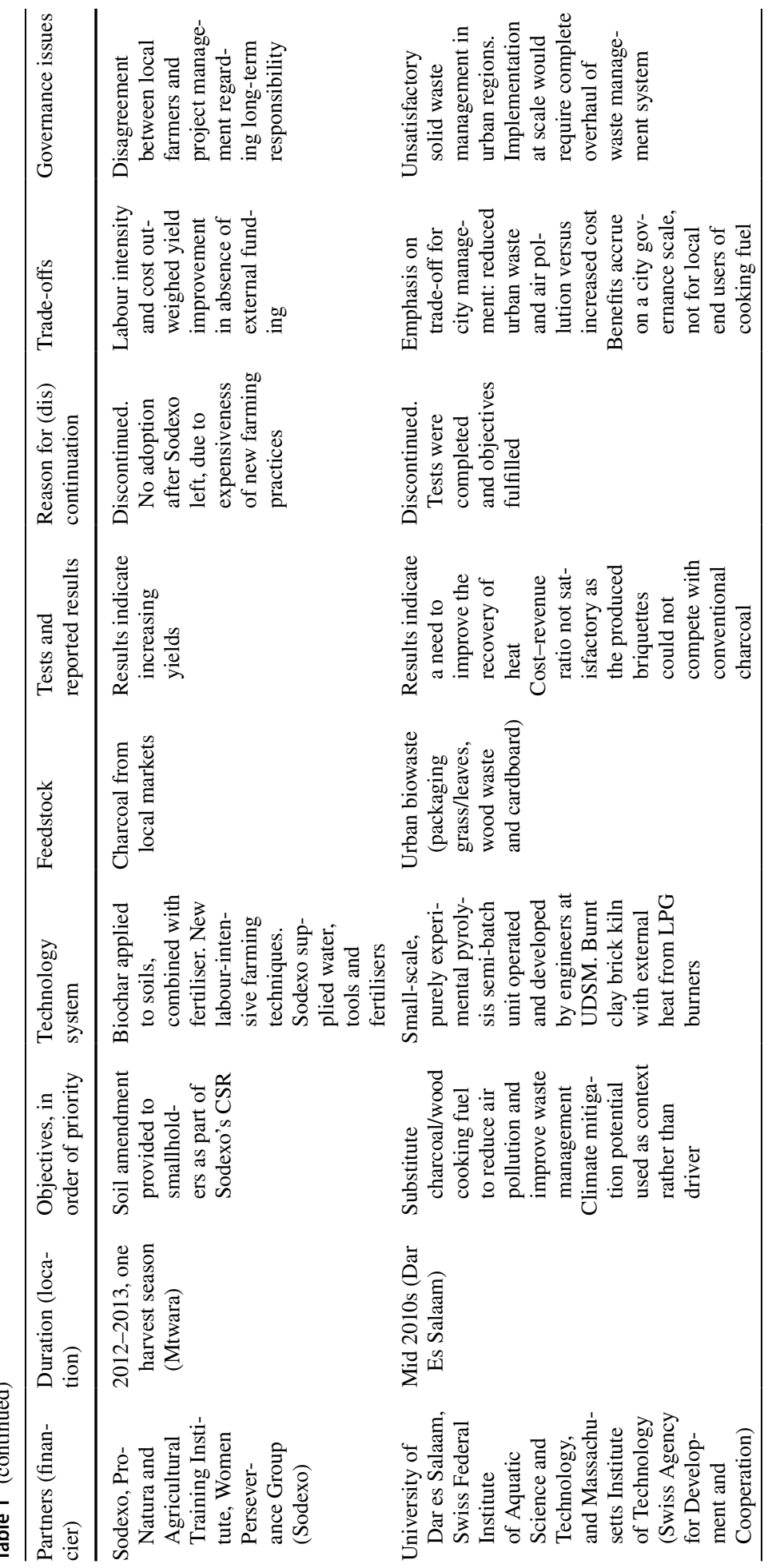




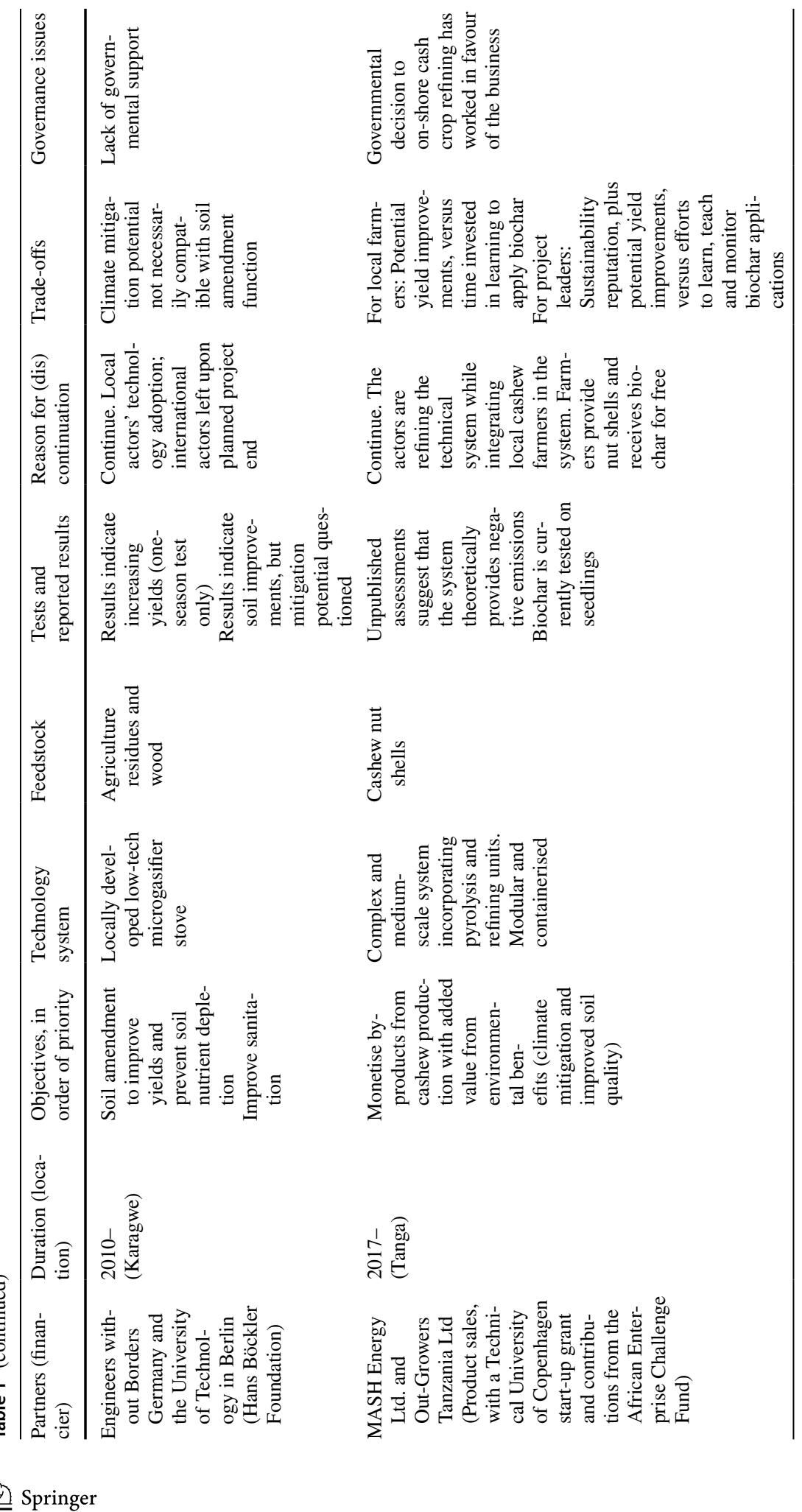




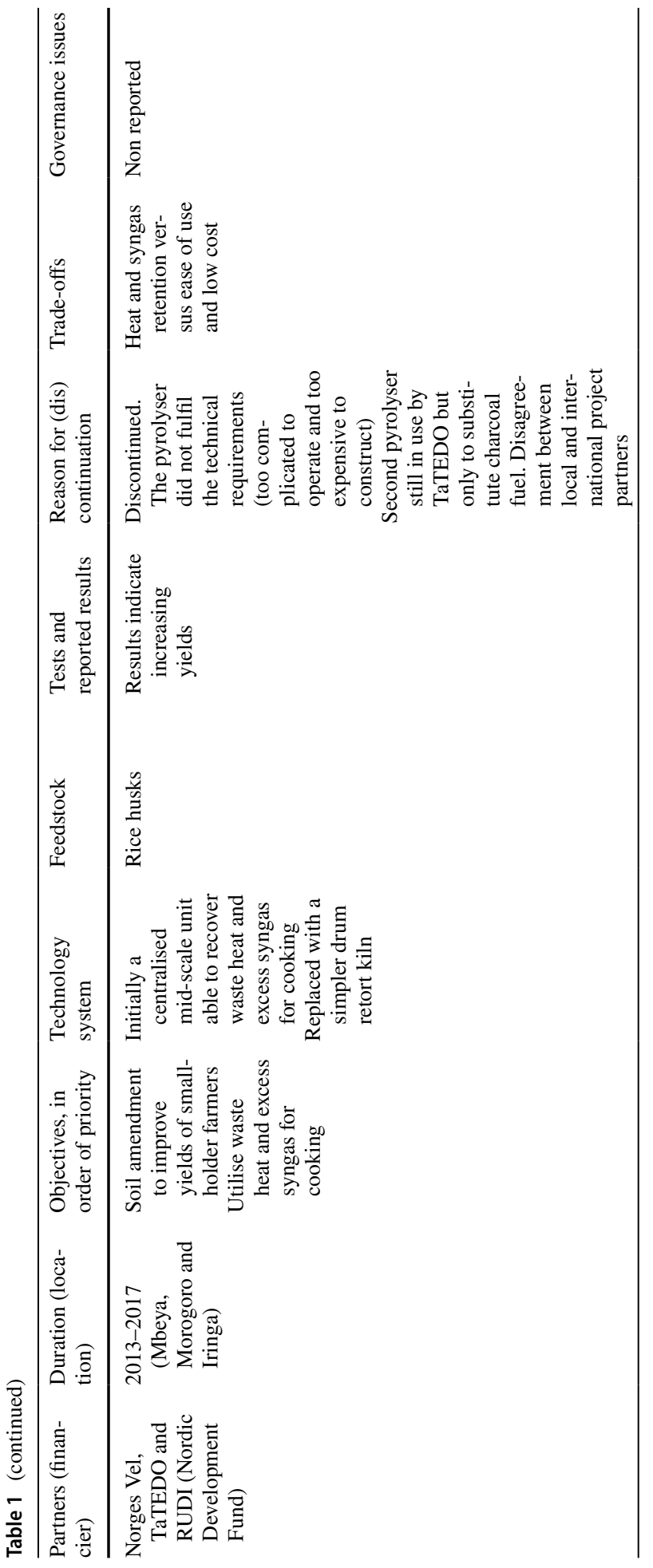




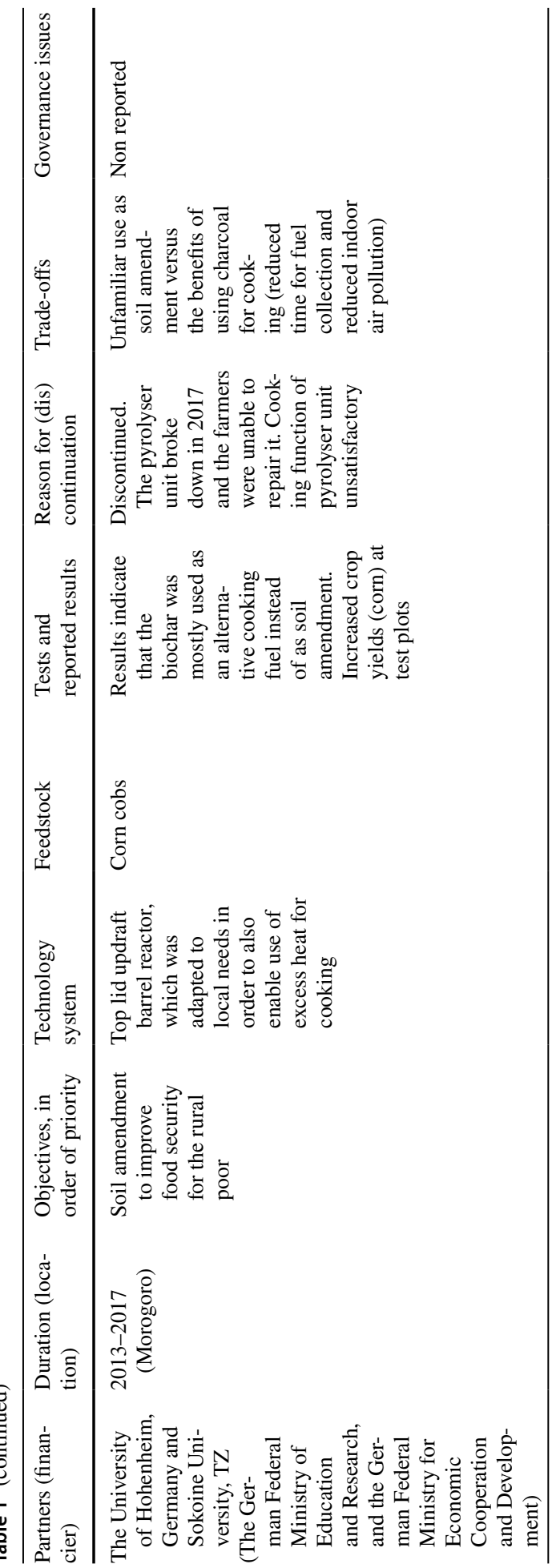




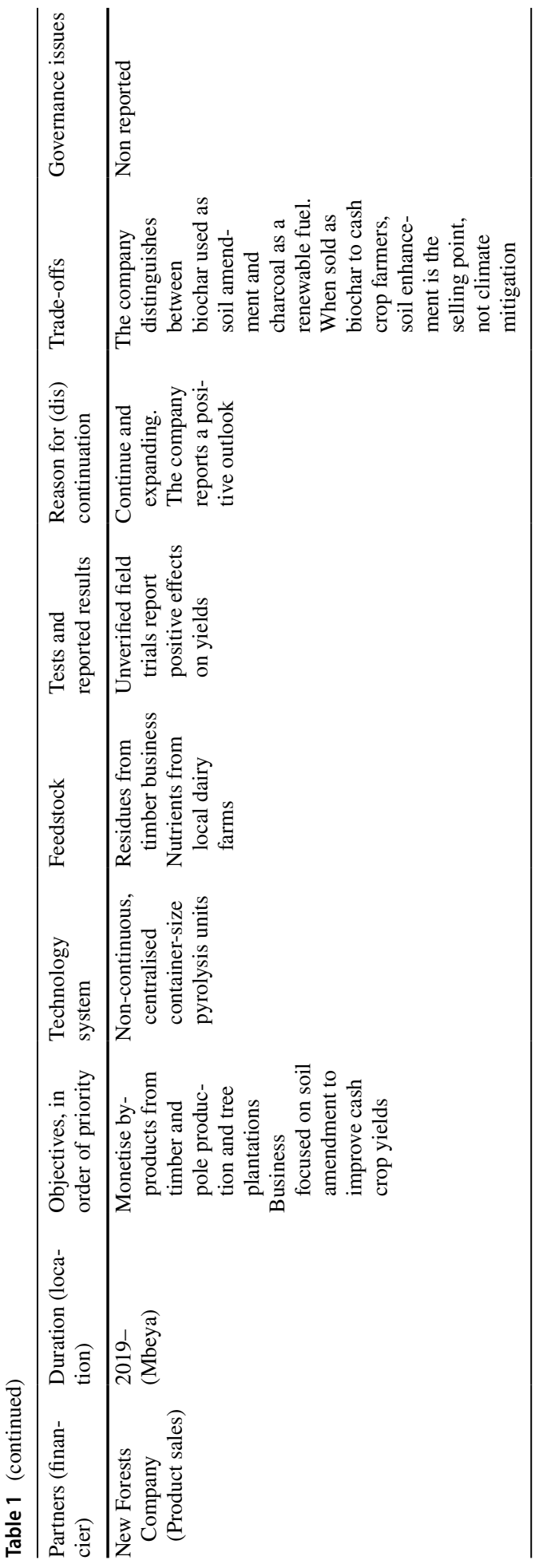




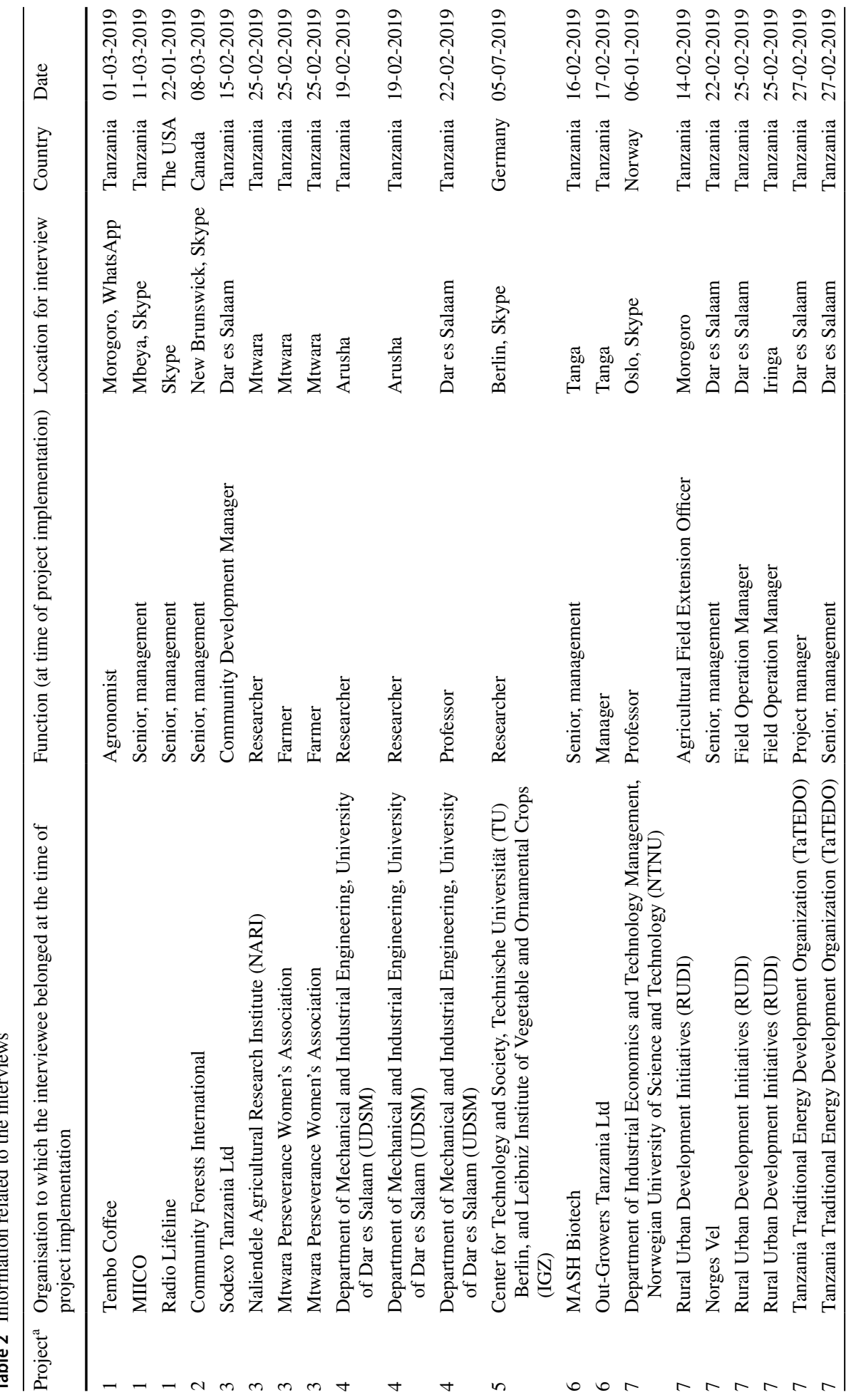




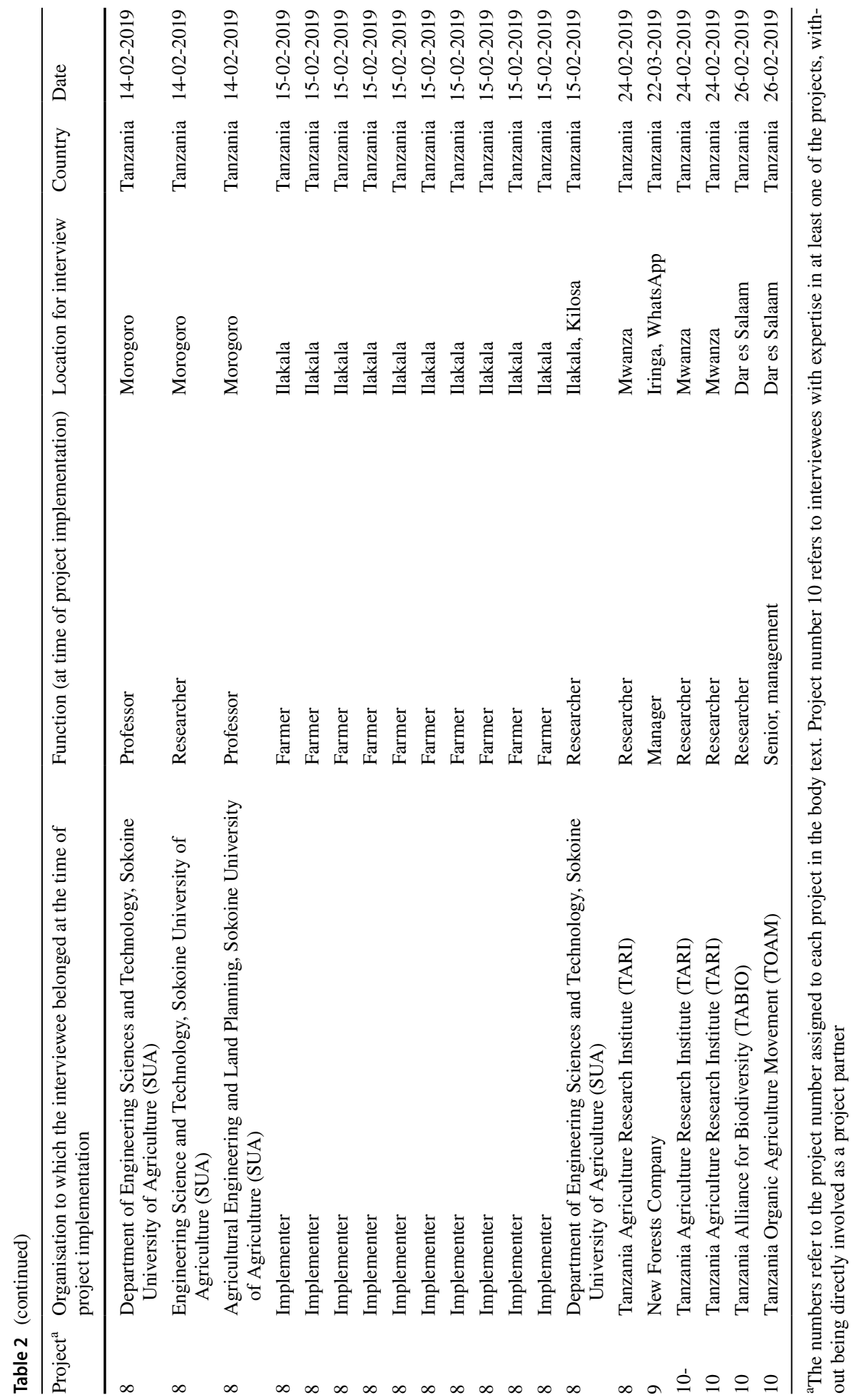




\section{Semi-structured interview guide}

Themes around which to focus the interview/discussion.

Overview: Rationale.

\section{Respondent's views on biochar and:}

Climate mitigation

1. Carbon content of biochar
a. feedstock properties
b. process optimisation choices.

2. Carbon stability in soils, mean residence time
a. feedstock properties
b. soil properties
c. weather conditions, soil moisture, microbes/worms.

3. Life cycle
a. Pre-mixing in soils (reduce biochar losses due to wind/water erosion).
b. Production-related land use change (source or sink).
c. Transport (mode, distance, weight/moisture content).
d. Climate opportunity costs (alternative usage/substitute).

Climate adaptation and yield capacity

1. improved soil properties, $\mathrm{pH}$

2. reduced soil erosion potential

3 . increased nutrient retention

4. water conservation/increased water retention.

Other co-benefits (with potential adaptation/mitigation overlaps)

1. replacing charcoal for cooking

2. off-grid electricity

3. fuel

4. sanitation.

Economy/logistics

1. Collection of feedstocks.

2. Supply and availability (costs, distance, seasonal variation, physical properties: dry bulk density, particle size uniformity, moisture content, fixed carbon content and ash content).

3. Competing use, economic opportunity costs.

4. Business model, market offset, demand, investment capital. 
5. Scale and location: smallholder farms versus ranches, rural versus urban, village versus industrial use.

\section{Challenges}

1. Research gaps (contextual knowledge regarding soils and feedstock and climate differences. Generalisations from local projects, lab studies and preta soils?).

2. Financial constraints (Access to low-cost and long-term financing).

3. Political constraints (monitoring, institutional frameworks, relation to charcoal politics, local customs).

4. Cultural constraints (stakeholders' perceptions and experiences)

\section{Implementation and dilemmas}

1. Batch reactor versus continuous reactor (simple, cheap and produced on material available locally with no heat recovery vs. a more technically sophisticated, expensive and reliable alternative with higher yields and heat recovery and more output flexibility). A matter of scale, cost, complexity and performance.

2. Which are the 'low-hanging fruits' (e.g. primarily small gardens for peri-urban and rural households (Gwenzi et al 2015), municipal waste, industrial waste (Lohri et al. 2015), ideal for households without access to electricity?)

3. What about the actors involved in charcoal?.

\section{Critique/risks:}

1. Monocultures (biodiversity, food security).

2. Land-grab.

3. Foreign involvement, conservation fad.

4. Poorly engineered/operated pyrolysis plants (negates mitigation effects, lack of knowledge concerning operation and maintenance).

Project-specific questions, as appropriate.

\section{References}

Adam, J. C. (2009). Improved and more environmentally friendly charcoal production system using a low-cost retort-kiln. Renewable Energy, 34, 1923-1925.

Adegbeye, M. J., Ravi Kanth Reddy, P., Obaisi, A. I., Elghandour, M. M., Oyebamiji, K. J., Salem, A. Z., Morakinyo-Fasipe, O. T., Cipriano-Salazar, M., \& Camacho-Díaz, L. M. (2020). Sustainable agriculture options for production, greenhouse gasses and pollution alleviation, and nutrient recycling in emerging and transitional nations-An overview. Journal of Cleaner Production, 242, 118319.

Alberti, G. (2013). A story of cooperation with Western Africa on biochar technology transfer. Technical report. Project BeBi: Agricultural and environmental benefits from biochar use in ACP countries. University of Udine.

Anderson, K., \& Peters, G. (2016). The trouble with negative emissions. Science, 354, 182-183.

Barrow, C. J. (2012). Biochar: Potential for countering land degradation and for improving agriculture. Applied Geography, 34, 21-28. 
Beesley, L., \& Marmiroli, M. (2011). The immobilisation and retention of soluble arsenic, cadmium and zinc by biochar. Environmental Pollution, 159, 474-480.

Beusekom, M., \& Hodgson, D. (2000). Lessons learned? Development experiences in the late colonial period. The Journal of African History, 41, 29-33.

Bidlingmaier, T. (Ed.) (2017). Coffee and prosperity: A perfect blend. The coffee partnership for Tanzania, final report. Cologne: DEG.

Billa, S. F., Angwafo, T. E., \& Ngome, A. F. (2019). Agro-environmental characterization of biochar issued from crop wastes in the humid forest zone of Cameroon. International Journal of Recycling of Organic Wastes in Agriculture, 8, 1-13.

Biochar International. (2018). Biochar carbon offset manual. Retrieved December 1, 2019, from https:// biochar-international.org/protocol.

Bracking, S. (2015). Performativity in the green economy: How far does climate finance create a fictive economy? Third World Quarterly, 36(12), 2337-2357.

Brockington, D., \& Ponte, S. (2015). The green economy in the global south: Experiences, redistributions and resistance. Third World Quarterly, 36(12), 2197-2206.

Brown, N. (2017). Low-cost biochar application in Tanzania shows astounding increases. Daily Coffe News 18 July. Retrieved May 25, 2019, from https://dailycoffeenews.com/2017/07/18/low-costbiochar-application-in-tanzania-shows-astounding-increases.

Buck, H. J. (2016). Rapid scale-up of negative emissions technologies: Social barriers and social implications. Climate Change, 139, 155-167.

Business Wire. (2013). New initiative equips farmers to combat climate change and increase food security. Business Wire 18 February. Retrieved February 2, 2019, from www.businesswire.com/news/ home/20130218005057/en/New-Initiative-Equips-Farmers-Combat-Climate-Change.

Carton, W., \& Andersson, E. (2017). Where forest carbon meets its maker: Forestry-based offsetting as the subsumption of nature. Society \& Natural Resources, 30(7), 829-843.

CFI (2019). Can we solve Tanzania's big charcoal question one small answer at a time? Retrieved May 1, 2019, from https://forestsinternational.org/innovation/post/can-we-answer-tanzanias-charcoalquestion-one-small-answer-at-a-time.

Cosmidis, L., \& Siwingwa, A. (2017). Biochar IVS project Tembo-MIICO, Final report. Unpublished.

Cowie, A., Woolf, D., Gaunt, J., Brandao, M., de la Rosa, R. A., \& Cowie, A. (2015). Biochar, carbon accounting and climate change. In J. Lehmann \& S. Joseph (Eds.), Biochar for environmental management: Science and technology (2nd ed., pp. 763-794). London: Earthscan.

Creutzig, F., Ravindranath, N. H., Berndes, G., Bolwig, S., Bright, R., Cherubini, F., et al. (2015). Bioenergy and climate change mitigation: An assessment. Global Change Biology Bioenergy, 7(5), 916-944.

Death, C. (2012). Environmental mainstreaming and post-sovereign governance in Tanzania. Journal of Eastern African Studies, 7, 1-20.

Edstedt, K., \& Carton, W. (2018). The benefits that (only) capital can see? Resource access and degradation in industrial carbon forestry, lessons from the CDM in Uganda. Geoforum, 97, 315-323.

Ernsting, A., \& Smolker, R. (2011). A critical review of biochar science and policy. Biofuelwatch report.

Exner, A., Bartels, L. E., Windhaber, M., Fritz, S., See, L., Politti, E., et al. (2015). Constructing landscapes of value: Capitalist investment for the acquisition of marginal or unused. Land Use Policy, $42,652-663$

FAO. (2017). The charcoal transition: Greening the charcoal value chain to mitigate climate change and improve local livelihoods. Rome: Food and Agriculture Organization of the United Nations.

Faran, T., \& Olsson, L. (2018). Geoengineering: Neither economical, nor ethical-A risk-reward nexus analysis of carbon dioxide removal. International Environmental Agreements: Politics, Law and Economics, 18, 63-77.

Felix, M., \& Gheewala, S. H. (2011). A review of biomass energy dependency in Tanzania. Energy Procedia, 9, 338-343.

Fridahl, M., Hagemann, M., Roser, F., \& Amars, L. (2015). A comparison of design and support priorities of Nationally Appropriate Mitigation Actions (NAMAs). The Journal of Environment \& Developement, 24(2), 237-264.

Fuss, S., et al. (2014). Betting on negative emissions. Nature Climate Change, 4, 850-853.

Garcia-Nunez, J. A., Pelaez-Samaniego, M. R., \& Garcia-Perez, M. E. (2017). Historical developments of pyrolysis reactors: A review. Energy \& Fuels, 31(6), 5751-5775.

Gaunt, J., \& Driver, K. (2010). Bringing biochar projects into the C marketplace: An introduction to biochar science, feedstocks and technology. Calgary: Carbon Consulting and Blue Source.

Gaunt, J., \& Lehmann, J. (2008). Energy balance and emissions associated with biochar sequestration and pyrolysis bioenergy production. Environmental Science and Technology, 42, 4152-4158. 
Geden, O. (2015). Climate advisers must maintain integrity. Nature, 521, 27-28.

Gough, C., Garcia-Freites, S., Jones, C., \& Mander, S. (2018). Challenges to the use of BECCS as a keystone technology in pursuit of $1.5^{\circ} \mathrm{C}$. Global Sustainability, 1, 1-9.

Gould, J., \& Ojanen, J. (2003). Mergin in the circle: The politics of Tanzania's poverty reduction strategy. Policy papers 2/2003. Helsinki: Institute of development studies, University of Helsinki.

Graef, H., Kiobia, D., Saidia, P., Kahimba, F., Graef, F., \& Eichler-Löbermann, B. (2018). Combined effects of biochar and fertilizer application on maize production in dependence on the cultivation method in a sub-humid climate. Communication in Soil Science \& Plant Analysis, 49(22), 2905-2917.

Güereña, D. T., Kimetu, J., Riha, S., Neufeldt, H., \& Lehmann, J. (2015). Maize productivity dynamics in response to mineral nutrient additions and legacy organic soil inputs of contrasting quality. Field Crops Research, 188, 113-120.

Gwenzi, W., Chaukura, N., Mukome, F., Machado, S., \& Nyamasoka, B. (2015). Biochar production and applications in sub-Saharan Africa: Opportunities, constraints, risks and uncertainties. Journal of Environmental Management, 150, 250-261.

Hagemann, N., Joseph, S., Schmidt, H. P., Kammann, C. I., Harter, J., Borch, T., et al. (2017). Organic coating on biochar explains its nutrient retention and stimulation of soil fertility. Nature Communications, 8,1089 .

Hansen, U., Nygaard, I., Romijn, H., Wieczorek, A., Kamp, L., \& Klerkx, L. (2018). Sustainability transitions in developing countries: Stocktaking, new contributions and a research agenda. Environmental Science and Policy, 84, 198-203.

Hansson, A., Haikola, S., Fridahl, M., Yanda, P., Pauline, N., \& Mabhuye, E. (2019). Pre-conditions for bioenergy with capture and storage (BECCS) in sub-Saharan Africa: The case of Tanzania. Environment, Development and Sustainability. https://doi.org/10.1007/s10668-019-00517-y.

Hardie, D. (2016). What! no rocket stove? Permaculture Magazine, 87, 51-54.

Harper, A. B., Powell, T., Cox, P. M., House, J., Huntingford, C., Lenton, T. M., et al. (2018). Land-use emissions play a critical role in land-based mitigation for Paris climate targets. Nature Communications, 9, 2938.

IPCC. (2018). Global Warming of $1.5^{\circ} \mathrm{C}$. An IPCC Special Report on the impacts of global warming of $1.5{ }^{\circ} \mathrm{C}$ above pre-industrial levels and related global greenhouse gas emission pathways, in the context of strengthening the global response to the threat of climate change, sustainable development, and efforts to eradicate poverty. Masson-Delmotte, V., Zhai, P., Pörtner, H. -O., Roberts, D., Skea, J., Shukla, P. R., Pirani, A., Moufouma-Okia, W., Péan, C., Pidcock, R., Connors, S., Matthews, J. B. R., Chen, Y., Zhou, X., Gomis, M. I., Lonnoy, E., Maycock, T., Tignor, M., \& Waterfield, T. (Eds.).

Iyang, H., Klerkx, L., \& Leeuwis, C. (2014). Functions and limitations of farmer cooperatives as innovation intermediaries: Findings from China. Agricultural Systems, 127, 115-125.

Jeffery, S., Verheijen, F. G. A., van der Velde, M., \& Bastos, A. C. (2011). A quantitative review of the effects of biochar application to soils on crop productivity using meta-analysis. Agriculture, Ecosystem and Environment, 144, 175-187.

Joseph, S., Anh, M. L., Clare, A., \& Shackley, S. (2015). Socio-economic feasibility, implementation and evaluation of small-scale biochar projects. In J. Lehmann \& S. Joseph (Eds.), Biochar for environmental management: Science and technology (2nd ed., pp. 853-879). London: Earthscan.

Jumbe, C. B. L., Msiska, F. B. M., \& Madjera, M. (2009). Biofuels development in Sub-Saharan Africa: Are the policies conducive? Energy Policy, 37, 4980-4986.

Kavitha, B., Reddy, P. V. L., Kim, B., Lee, S. S., Pandey, S. K., \& Kim, K.-H. (2018). Benefits and limitations of biochar amendment in agricultural soils: A review. Journal of Environmental Management, 227, 146-154.

Kilelu, C., Klerkx, L., Leeuwis, C., \& Hall, A. (2011). Beyond knowledge brokering: An exploratory study on innovation intermediaries in an evolving smallholder agricultural system in Kenya. Knowledge Management for Developmental Journal, 7(1), 84-108.

Kimetu, J. M., Lehmann, J., Ngoze, S. O., Mugendi, D. N., Kinyangi, J. M., Riha, S., et al. (2008). Reversibility of soil productivity decline with organic matter of differing quality along a degradation gradient. Ecosystem, 11, 726-739.

Klerkx, L., Pant, L. P., Leeuwis, C., Cummings, S., Le Borgne, E., Kulis, I., et al. (2011). Beyond the conventional boundaries of knowledge management: Navigating the emergent pathways of learning and innovation for international development. Knowledge Management for Developmental Journal, 7(1), $1-7$.

Krause, A. (2015). Participatory system analysis of an integrated approach to bio-energy production, ecological sanitation and sustainable food production. Berlin: Technische Universität Berlin.

Krause, A., \& Köppel, J. (2018). A multi-criteria approach for assessing the sustainability of small-scale cooking and sanitation technologies. Challenges in Sustainability, 6, 1-19. 
Krause, A., Nehls, T., George, E., \& Kaupenjohann, M. (2016). Organic wastes from bioenergy and ecological sanitation as a soil fertility improver: A field experiment in a tropical Andosol. Soil, 2, 147-162.

Krause, A., \& Rotter, V. S. (2018). Recycling improves soil fertility management in smallholdings in Tanzania. Agriculture, 8, 31 .

Kätterer, T., Roobroeck, D., Andrén, O., Kimutai, G., Karltun, E., Kirchmann, H., et al. (2019). Biochar addition persistently increased soil fertility and yields in maize-soybean rotations over 10 years in sub-humid regions of Kenya. Field Crops Res, 235, 18-26.

Lambe, F., Jürisoo, M., Carrie, L., \& Johnson, O. (2015). Can carbon finance transform household energy markets? A review of cookstove projects and programs in Kenya. Energy Research \& Social Science, 5, 55-66.

Lehmann, J., Gaunt, J., \& Rondon, M. (2006). Bio-char sequestration in terrestrial ecosystems-A review. Mitigation and Adaptation Strategies for Global Change, 11, 403-427.

Lehmann, J., Abiven, S., Kleber, M., Pan, G., Singh, B. P., \& Sohi, S. P. (2015). Persistence of biochar in soil. In J. Lehmann \& S. Joseph (Eds.), Biochar for environmental management: Science and technology (2nd ed., pp. 235-282). London: Earthscan.

Lehmann, J., \& Joseph, S. (Eds.). (2015). Biochar for environmental management: Science and technology (2nd ed.). London: Earthscan.

Locher, M., \& Sulle, E. (2014). Challenges and methodological flaws in reporting the global land rush: Observations from Tanzania. Journal of Peasant Studies, 41(4), 569-592.

Lohri, C. R., Faraji, A., Ephata, E., Rajabu, H. M., \& Zurbrügg, C. (2015). Urban biowaste for solid fuel production: Waste suitability assessment and experimental carbonization in Dar es Salaam, Tanzania. Waste Management \& Research, 33, 175-182.

Lund, J. F., Sungusia, E., Mabele, M. B., \& Scheba, A. (2016). Promising change, delivering continuity: REDD+ as conservation fad. World Development, 59, 124-139.

Luttrell, C., \& Pantaleo, I. (2008). Budget support, aid instruments and the environment: Tanzania case study, Technical report. London: Overseas Development Institute.

Maraseni, T., Chen, G., \& Guangren, Q. (2010). Towards a faster and broader application of biochar: Appropriate marketing mechanisms. International Journal of Environmental Studies, 67(6), 851-860.

Mash-Energy. (2019). New value from waste. Retrieved May 1, 2019, from www.mash-energy.com.

McLaren, D., Tyfield, D. P., Willis, R., Szerszynski, B., \& Markusson, N. O. (2019). Beyond "net-zero": A case for separate targets for emissions reduction and negative emissions. Frontiers in Climate, 1, 4.

Mehmood, K., Garcia, E. C., Schirrmann, M., Ladd, B., Kammann, C., Wrage-Mönnig, N., et al. (2017). Biochar research activities and their relation to development and environmental quality. A meta analysis. Agronomy for Sustainable Developement, 37, 22.

Middendorf, B. J., Pierzynski, G. M., Stewart, Z. P., \& Prasad, P. V. V. (2017). Sub-Saharan Africa soil fertility prioritization report: II. Summit results. Manhattan: Kansas State University.

Mosoba, T. (2019). Haraambe' model revives hope in cashew farming. The Citizen 28 March. Retrieved May 15, 2019, from www.thecitizen.co.tz/magazine/-Harambee--model-revives-hope-in-cashe w-farming-/1840564-5046352-58ha6tz/index.html.

Mshandete, A. M. (2011). Biofuels in Tanzania: Status, opportunities and challenges. Journal of Applied Bioscience, 40, 2677-2705.

Mulcahy, D. N., Mulcahy, D. L., \& Dietz, D. (2013). Biochar soil amendment increases tomato seedling resistance to drought in sandy soils. Journal of Arid Environments, 88, 222-225.

Mwansasu, S. L. A., \& Westerberg, L. O. (2014). Biofuel potential and land availability: The case of Rufiji District, Tanzania. Journal of Ecology and the Natural Environment, 6, 389-397.

NCF. (2017). Final report: From waste to local business development and vigorous soil, Tanzania. Helsinki: Nordic Climate Facility.

NFC. (2019). The new forests company - sustainability report 2019. Retrieved June 18, 2020, from http:// newforests.net/about-us/sustainability-reports/.

Olwiga, M. F., Noe, C., Kangalawe, R., \& Luoga, E. (2015). Inverting the moral economy: The case of land acquisitions for forest plantations in Tanzania. Third World Quarterly, 36(12), 2316-2336.

Pansera, M., \& Sarkar, S. (2016). Crafting sustainable development solutions: Frugal innovations of grassroots entrepreneurs. Sustainability, 8, 1-51.

Paustian, K., Brenner, J., Easter, M., Killian, K., Ogle, S., Olson, C., et al. (2009). Counting carbon on the farm: Reaping the benefits of carbon offset programs. Journal of Soil and Water Conservation, 64, $36 \mathrm{~A}-40 \mathrm{~A}$

Pro-Natura. (2012). Greening the Sahara with biochar while fighting climate change. Pro-Natura newsletter, March. Retrieved April 26, 2019, from www.pronatura.org/wp-content/uploads/2012/03/ Greening-the-Sahara-with-Biochar-2012.pdf. 
Ramos-Mejía, M., Franco-Garcia, M. L., \& Jauregui-Becker, J. M. (2018). Sustainability transitions in the developing world: Challenges of socio-technical transformations unfolding in contexts of poverty. Environmental Science \& Policy, 84, 217-223.

Rascack, B. (2014). Forest reform in Tanzania: A review of policy and legislation. African Journal of Economic Review, 11(2), 125-149.

RGZ. (2013). Zanzibar woody biomass survey preparedness for REDD+ phase. The revolutionary government of Zanzibar. Dodoma: Ministry of Agriculture and Natural Resources. Department of Forestry and Non-Renewable Natural Resources.

Robbins, P. (2008). The state in political ecology: A postcard to political geography from the field. In K. Cox, et al. (Eds.), The Sage handbook of political geography (pp. 205-218). London: Sage.

Roberts, K. G., Gloy, B. A., Stephen, J., Scott, N. R., \& Lehmann, J. (2010). Life cycle assessment of biochar systems: Estimating the energetic, economic, and climate change potential. Environmental Science \& Technology, 44(2), 827-833.

Romijn, H., Raven, R., \& de Visser, I. (2010). Biomass energy experiments in rural India: Insights from learning-based development approaches and lessons for Strategic Niche Management. Environmental Science \& Policy, 13, 326-338.

Schmidt, H.-P., Anca-Couce, A., Hagemann, N., Werner, C., Gerten, D., Lucht, W., et al. (2018). Pyrogenic carbon capture and storage (PyCCS). Global Change Biology: Bioenergy, 11, 573-591.

Scholz, S., Sembres, T., Roberts, K., Whitman, T., Wilson, K., \& Lehmann, J. (2014). Biochar systems for smallholders in developing countries: Leveraging current knowledge and exploring future potential for climate-smart agriculture. Washington, DC: World Bank Studies.

Shaaban, M., Van Zwieten, L., Bashir, S., Younas, A., Núñez-Delgado, A., Chhajro, M. A., et al. (2018). A concise review of biochar application to agricultural soils to improve soil conditions and fight pollution. Journal of Environmental Management, 228, 429-440.

Shackley, S., \& Carter, S. (2014). Biochar stoves: An innovation studies perspective. In E. Sajor, B. Resurreccion, \& S. Rakshit (Eds.), Bio-innovation and poverty alleviation: Case studies from Asia. New Dehli: SAGE Publications Ltd.

Shackley, S., Hammond, J., Gaunt, J., \& Ibarrola, R. (2011). The feasibility and costs of biochar deployment in the UK. Carbon Management, 2, 335-356.

Sinton, J. E., Smith, K. R., Peabody, J. W., Yaping, L., Xiliang, Z., Edwards, R., et al. (2004). An assessment of programs to promote improved household stoves in China. Energy for Sustainable Developement, 3, 33-52.

Smith, A., Fressolli, M., \& Thomas, H. (2014). Grassroots innovation movements: Challenges and contributions. Journal of Cleaner Production, 63, 114-124.

Smith, P. (2016). Soil carbon sequestration and biochar as negative emission technologies. Global Change Biology, 22, 1315-1324.

Sodexo (n.d.). Super vegetable garden trial report. Unpublished.

Sodexo (n.d.B). Implementation of a super vegetable garden-Perseverance project. Unpublished.

Sosovele, H. (2014). Moratorium in biofuel development projects in Tanzania: The need for policies, guidelines and sustainability criteria. Journal of Geographical Association of Tanzania, 34(1-2), $1-25$.

Spokas, K. A., Cantrell, K. B., Novak, J. M., Archer, D. W., Ippolito, J. A., Collins, H. P., et al. (2012). Biochar: A synthesis of its agronomic impact beyond carbon sequestration. Journal of Environmental Quality, 41(4), 973-989.

Swilling, M., Musango, J., \& Wakeford, J. (2016). Developmental states and sustainability transitions: Prospects of a just transition in South Africa. Journal of Environmental Policy and Planning, 18, 650-672.

Thies, J. E., Rillig, M. C., \& Graber, E. R. (2015). Biochar effects on the abundance, activity and diversity of the soil biota. In J. Lehmann \& S. Joseph (Eds.), Biochar for environmental management: Science and technology (2nd ed., pp. 327-389). London: Earthscan.

Uckert, G., Löhr, K., Graef, F., \& Sieber, S. (2018). The trans-SEC book of participative research approaches for implementing food securing upgrading strategies. Müncheberg: Leibniz Centre for Agricultural Landscape Research.

Unruh, J. D. (2008). Carbon sequestration in Africa: The land tenure problem. Global Environmental Change, 18, 700-707.

van der Gast, W. P., \& Spijker, E. (2013). Biochar and the carbon market: A review of carbon market development perspectives and biochar offset projects GHG accounting aspects. Groningen: Joint Implementation Network.

van Lente, H., Hekkert, M., Smits, R., \& van Waveren, B. (2003). Roles of systemic intermediaries in transition processes. International Journal of Innovation Management, 7(3), 247-279. 
van Welie, M., \& Romijn, H. (2018). NGOs fostering transitions towards sustainable urban sanitation in low-income countries: Insights from transition management and development studies. Environmental Science Policy, 84, 250-260.

Verbong, G., Christiaens, W., Raven, R., \& Balkema, A. (2010). Strategic Niche management in an unstable regime: Biomass gasification in India. Environmental Science Policy, 13(4), 272-281.

Verheijen, F., Jones, R. J. A., Rickson, R. J., \& Smith, C. J. (2009). Tolerable versus actual soil erosion rates in Europe. Earth-Science Review, 94(1-4), 23-38.

Verheijen, F. G. A., Montanarella, L., \& Bastos, A. C. (2012). Sustainability, certification, and regulation of biochar. Pesquisa Agropecuária Brasileira, 47(5), 649-653.

Verheijen, F., et al. (2010). Biochar application to soils-A critical scientific review of effects on soil properties, processes and functions. Luxembourg: Office for the Official Publications of the European Communities.

Whitman, A., \& Lehmann, J. (2009). Biochar-One way forward for soil carbon in offset mechanisms in Africa? Environmental Science and Policy, 12, 1024-1027.

Wieczorek, A. (2018). Sustainability transitions in developing countries: Major insights and their implications for research and policy. Environmental Science and Policy, 84, 204-216.

Woolf, D., Amonette, J., Street-Perrott, F., Lehmann, J., \& Joseph, S. (2010). Sustainable biochar to mitigate global climate change. Nature Communications, 1, 56.

World Bank. (2013). Unlocking Africa's agriculture potential. Washington, DC: The World Bank.

Yaman, S. (2004). Pyrolysis of biomass to produce fuels and chemical feedstocks. Energy Conversion and Management, 45, 651-671.

Publisher's Note Springer Nature remains neutral with regard to jurisdictional claims in published maps and institutional affiliations. 